\title{
The Pre-Commitment Approach: Using Incentives to Set Market Risk Capital Requirements
}

\author{
Paul H. Kupiec and James M. O’Brien ${ }^{\dagger}$
}

March 1997

${ }^{\dagger}$ Trading Risk Analysis Section, Division of Research and Statistics, Board of Governors of the Federal Reserve System. The conclusions herein are those of the authors and do not represent the views of the Federal Reserve Board or any of the Federal Reserve Banks. The authors are indebted to Mark Fisher for many helpful discussions and to Greg Duffee for his comments on earlier drafts of this paper. Contact Paul Kupiec, Mail Stop 91, Federal Reserve Board, Washington, DC, 20551, 202-452-3723, or email pkupiec@frb.gov. 


\begin{abstract}
This paper develops a model of bank behavior that focuses on the interaction between the incentives created by fixed rate deposit insurance and a bank's choice of its loan portfolio and its portfolio of market-traded financial assets. The model is used to analyze the consequences of adopting the Federal Reserve Board's proposed PreCommitment Approach (PCA) for setting capital requirements for the market risks of a bank's trading portfolio. Under the PCA, a bank sets its own market risk capital requirement with the knowledge that it will face regulatory penalties should its trading activities generate subsequent losses that exceed its market risk capital pre-commitment.
\end{abstract}




\section{The Pre-Commitment Approach: Using Incentives to Set Market Risk Capital Requirements}

\section{Introduction}

It is well-known that the provision of fixed-rate deposit insurance creates problems of moral hazard and adverse selection that must be attenuated through supplementary supervision and regulation. Prior to the implementation of the Basle Accord in 1992, in the U.S., supplementary regulation in part took the form of uniform minimum capital standards that were applied to all banks regardless of differences in their risk profiles. The task of limiting banks' risks and ensuring capital adequacy was left to regulatory monitoring and direct supervision. The Basle Accord altered this regulatory environment by establishing international minimum capital guidelines that linked banks' capital requirements to their credit risk exposures. More recently, the Basle Supervisory Committee (BSC) extended the 1988 Basle Accord to include riskbased capital requirements for the market risks in bank trading accounts. ${ }^{1}$

At present, the BSC market risk capital standards consist of two alternative approaches for setting regulatory capital requirements for trading positions. One approach, the Standardized Approach (Basle (1993), revised FRB (July 1995a)), is a set of rules that assign risk charges to specific instruments and specify how these charges are to be aggregated into an overall market risk capital requirement. The second BSC approach, the Internal Models Approach (Basle (April 1995), and FRB (July 1995a)) bases market risk capital charges on potential loss estimates generated by banks' internal risk measurement models. Under the internal models approach, a bank uses its proprietary risk measurement models to estimate a measure of its trading account's

\footnotetext{
${ }^{1}$ It is common to decompose market risk into two components: general market risk and specific market risk. General market risk is the risk that asset values will fluctuate owing to broad-based movements in securities prices and to changes in exchanges rates and commodity prices. Specific market risk is the risk that asset value will fluctuate owing to idiosyncratic developments. Market risk capital standards have been proposed only for positions in the trading account and bank-wide foreign exchange and commodity positions.
} 
market risk exposure. A general market risk regulatory capital requirement is set according to a formula which includes the exposure estimate as the primary input. There is also a separate capital charge for issuer-specific risk. ${ }^{2}$

The current BSC-approved standards for setting market risk capital requirements have inherent weaknesses that reduce their appeal as for controlling banks' market risk exposure. ${ }^{3}$ The Standardized Approach embodies risk measures that produce inaccurate estimates of the risk exposures that bank portfolios generate for the bank insurance fund (BIF). A system of capital requirements based on distorted risk measures can reduce economic efficiency by distorting banks' investment decisions and creating incentives for unproductive regulatory arbitrage activities. Although the Internal Models Approach was designed in an attempt to improve the accuracy of the Standardized Approach risk measures, because it extrapolates a long-horizon exposure estimate from a bank's internally generated 1-day market risk exposure estimate, it also fails to accurately measure the market risk in bank trading accounts. In particular, the Internal Models Approach methodology cannot account for a bank management's subjective risk assessments that augment their model-based estimates nor can it account for the material effects engendered by active risk management in determining risk exposure over a relatively lengthy horizon. Moreover, accuracy considerations require some method for validating each bank's internal risk exposure estimate. Statistical model validation is inherently problematic (Kupiec (1995)). Indeed, even under the most favorable conditions, there is a significant probability that regulators will be unable to detect poorly performing risk management models.

\footnotetext{
${ }^{2}$ The general market risk estimate must correspond to a loss that would be exceeded with less than 1 percent probability over a 10-day horizon. Subject to regulator discretion, the Internal Models Approach also provides for an increase in the capital requirement should a bank's model estimate fail prescribed statistical verification tests. The issuer-specific risk estimate may be based on bank internal model estimates but must be at least 50 percent of that which would result from the use of the standardized approach.

${ }^{3}$ For discussions on the BSC Standardized Approach, see Dimson and Marsh (1995), Kupiec and O'Brien (1996b). Kupiec and O'Brien (1995a, 1995c, 1996a, 1996b) review and critique the Internal Models Approach.
} 
In recognition of the weaknesses inherent in the BSC's market-risk capital standards, the Federal Reserve Board (July 1995b) requested public comment on an alternative approach, the so-called Pre-commitment Approach or PCA. The PCA would require a bank to pre-commit to a maximum loss exposure for its trading account positions over a fixed subsequent period. This maximum loss pre-commitment is the bank's market risk capital charge. Should the bank incur trading losses that exceed its capital commitment, it would be subject to penalties. Under the PCA, the bank's maximum loss pre-commitment can reflect the bank's internal risk assessmentsincluding formal model estimates and management's subjective judgments - as well as management's assessments of its ability to manage its risks over the commitment period. As a consequence, the PCA has the potential to remove the weaknesses inherent in the existing market risk capital regulations. The PCA incorporates penalties to provide banks with the incentive to commit capital consistent with their intended market risk exposure and risk management capabilities.

Although the PCA can be viewed as an alternative way to utilize banks' internal risk measurements in setting regulatory capital requirements, its design is markedly different from existing standards. The PCA attempts to supplant regulatory capital requirements that are based on ex ante estimates of bank risk with a capital requirement that is set endogenously through the optimal resolution of an incentive contract between the bank and its regulator. Under monetary penalties, it will be shown that the PCA takes the form of a put option written on the bank's assets and issued to the regulator (deposit insurer). Through the pre-commitment, the exercise price of this put option is under the control of the bank's management. The value of the bank's PCA liability will depend on the penalty rate set by the regulator, on the bank's pre-commitment, and on its chosen risk exposure. While formal incentive mechanism approaches to bank regulation have been discussed in the literature (e.g., John, John and Senbet (1991), Chan, Greenbaum, and Thakor (1992), Giammarino, Lewis, and Sappington (1993)), none of these have been formally considered by a bank regula- 
tory agency. This paper models the PCA and its incentive structure and analyzes its efficacy within a theoretical model of the banking firm.

In the following sections, a model of bank behavior is developed under a fixed rate deposit insurance (FRI) system. In this setting, the effects of a PCA market risk capital requirement are formally analyzed under an incentive structure in which violating banks face contingent supplemental deposit insurance premium. The analysis establishes conditions under which the PCA removes the moral hazard risks created by FRI and aligns bank market risk-taking incentives with those of the BIF.

\section{Bank Shareholder Value}

The bank is assumed to make investment and financing decisions in period 1 so as to maximize the net present value of its shareholders' claims on future bank cash flows. On the asset side, the bank may choose to invest in 1-period risky non-traded loans, risk-free discount bonds, and risky market-traded securities. Market-traded securities are assumed to be zero net present value (NPV) investments so that their risk-adjusted expected returns are equal to the risk-free rate. The total bank investment in risk-free bonds and risky securities investments are denoted by $T$ and $M$, respectively.

The end-of-period values of individual loans or risky security investments are assumed to have lognormal distributions. Although not critical to the qualitative results of the model, the log-normality assumption simplifies valuations. Accordingly, the end-of-period value of a generic investment $i$ in a loan or risky security, $j_{i 1}$, is given by,

$$
j_{i 1}=V_{i} e^{\mu_{i}+s_{i}^{\top} z_{1}}
$$

where $V_{i}$ is the initial investment in the asset, $\mu_{i}$ is the expected rate of return (net

of any loan processing costs), $s_{i}$ is a vector of volatilities (superscript $T$ denotes transpose) and $z_{1}$ is a vector of independent standard normal shocks. The return 
variance is denoted by $\sigma_{i}^{2}=s_{i}^{\top} s_{i}$. The risk-adjusted present value of the investment, $j_{i 0}$, is given by

$$
j_{i 0}=V_{i} e^{\mu_{i}+\frac{1}{2} \sigma_{i}^{2}-\lambda^{\top} s_{i}-r}
$$

where $\lambda$ is a vector of the market prices of investment $i$ 's risk factors (non-systematic risks have a zero price), and $r$ is the 1 -period risk-free rate. ${ }^{4}$ The bank's valuation of asset $i$ satisfies a standard absence of arbitrage pricing condition. The bank is assumed to know the distributions of individual loan returns (expression (1)) and, while loans are not market-traded assets, their values to the bank's shareholders are assumed to be determined by expression (2). A single loan $i$, requires an investment of $I_{i}$, and has a positive $\operatorname{NPV}\left(j_{L_{i} 0}-I_{i}>0\right)$ if $\mu_{L_{i}}+\frac{1}{2} \sigma_{L_{i}}^{2}-\lambda^{\top} s_{L_{i}}-r>0$. A risky market-traded securities portfolio requires an investment of $M$ and has a zero NPV $\left(j_{M 0}-M=0\right)$ since $\mu_{M}+\frac{1}{2} \sigma_{M}^{2}-\lambda^{\top} s_{M}-r=0$. For simplicity, risk-free rates are assumed to be non-stochastic. ${ }^{5}$

The bank's loan investment opportunity set consists of all combinations of loans the bank might make (i.e., all possible loan portfolios). Each member of the loan opportunity set is characterized by four important characteristics (i) a required investment, (ii) a portfolio NPV, (iii) a vector of systematic (priced) risks, and (iv) a vector of non-systematic risks. In general, all four characteristics will be important quantities in the bank's optimization decision. This characterization of the loan investment opportunity set differs from that used in previous banking models where, if positive NPV loan opportunities were included, the bank was assumed to choose among loan portfolios in which NPV and risk were functionally related. ${ }^{6}$ Here, we do not assume there exists a particular relationship between loan portfolio NPV and risk

\footnotetext{
${ }^{4}$ See Appendix for a formal derivation of (2).

${ }^{5}$ The model could be generalized to include stochastic interest rates. This would complicate the pricing expressions without adding any additional insight into the issues of interest.

${ }^{6}$ Just a few of the many references include Gennotte and Pyle (1991), Campbell, Chan, and Marino (1992), Chan, Greenbaum, and Thakor (1992), Besanko and Kanatas (1996).
} 
as there appears to be no economic basis for making such an assumption. ${ }^{7}$ Moreover, loan portfolios must also be distinguished by the level of required investment if there are costs associated with external finance.

The bank finances its investments with a combination of internal equity capital, external equity finance, and insured deposits. Internal equity, $W$, represents the contribution of the initial shareholders. Outside equity financing, E, is assumed to generate issuance costs of $d_{0} \geq 0$ per dollar of equity issued. Issuance costs include normal transactions fees as well as any implicit asymmetric information costs that may in part take the observable form of payments to auditors and a reputable underwriter for certifying the value and risk of the issue. ${ }^{8}$

While deposits provide liquidity services, the model abstracts from modeling complications associated with demandable deposits and treats these accounts as 1-period discount bonds with an aggregate par value of $B$. As deposits are insured, their required return is equal to the 1-period risk-free rate, $r$, less a charge for liquidity services. It is assumed that the service charge earns the bank a profit of $\pi$ per dollar of deposits. It is convenient to assume that both the transactions account fees and the bank's fixed rate deposit insurance premium payments, denoted by $\phi B$, are paid at the beginning of the initial period. If the profit rate from deposits $(\pi)$ is constant and less than the insurance premium rate $(\phi)$, it would be optimal for a bank to attract unlimited deposits, invest them in risk-free securities, and make infinite risk-free profits. Such opportunities are ruled out by the assumption that the bank's maximum deposit base is fixed at $\bar{B}$ (par value), perhaps for geographical reasons.

In the model, short-selling of securities -including derivatives transactions that create implicit short positions - is prohibited. The potential liabilities created by

\footnotetext{
${ }^{7}$ The only theoretically established relationship between a traded assets's risk characteristics and its NPV comes from the absence of arbitrage condition. This relationship implies that, regardless of its risk characteristics, a traded asset's NPV=0. As loans are non-traded assets, they need not satisfy this condition.

${ }^{8} \mathrm{~A}$ natural source of asymmetric information arises when the bank's evaluation of its loans' risk and return characteristics differ from those of an outside investor.
} 
short positions are not insured. As a consequence, short positions expose a bank's counterparties to default (credit) risk that must be priced into the contract or mitigated through collateralization arrangements. Collateralization arrangements require estimates of risk exposures and may introduce significant complications in the valuation of the deposit insurance guarantee. Alternatively, to correctly account for the pricing effects engendered by credit risk, the complete specification of both bank and counterparty default conditions are required. ${ }^{9}$ Thus, the introduction of collateralization agreements and the explicit pricing of credit risk exposures would add significant complications to the model without, we believe, altering the qualitative results. To avoid these complications, the model excludes transactions that generate payout commitments other than those to shareholders and insured depositors.

At the end of the first period, the bank's cash-flows from its loans, risky securities, and risk-free bonds are used to payoff depositors. Shareholders receive any excess cash flows and retain rights to the bank's franchise value, $J$. If cash flow is insufficient to meet depositors' claims $(B)$, the bank may issue equity against its franchise value. The bank's franchise value is treated as an asset of fixed value. However, equity issued against $J$ to finance end-of-period cash flow shortfalls are assumed to generate "distress issuance costs" of $d_{1} \geq 0$ per dollar of issuance. The bank cannot accept new deposits before it satisfies its existing deposit liabilities. ${ }^{10}$ As with equity sales in non-distress periods, distress issuance costs would include both transactions fees

\footnotetext{
${ }^{9}$ In reality, pricing credit risk is more complicated. If a model includes equity issuance costs that arise in part from asymmetric information, then pricing contracts under the assumption that defaulting states are known a priori by counterparties will lead to valuation inconsistencies. For logical consistency, a model that assumes outside equity issuance is costly owing to asymmetric information must also reflect such costs in the pricing of credit risk exposures as the asymmetric information problems of the bank's counterparties are analogous to those of its outside investors.

${ }^{10}$ If the bank is insolvent, the equity sales costs represent the cost absorbed by the deposit insurer when it takes over the bank and sells its assets or seeks a merger partner. The assumption that the bank is prohibited from accepting new deposits before it pays off its existing deposit liabilities could be relaxed if the deposit insurer was required to audit a cash-deficient bank - charging the bank a fair audit fee roughly equivalent to the distress issuance cost faced by the bank-and approve the deposit roll-over funding only if the audit found that the franchise value covered the cash deficiency and audit costs.
} 
and costs for certifying the value of the issue.

Let L represent the set of individual loans in the bank's optimal loan portfolio. Under these assumptions, the net present value of initial shareholder's claims is given by ${ }^{11}$

$$
\begin{aligned}
S & =j_{L 0}-I+e^{-r} J+\pi B e^{-r}+P_{I}-\phi B e^{-r} \\
& +\frac{d_{1}}{1-d_{1}}\left(P_{I}-P_{D}\right)-\frac{d_{0}}{1-d_{0}} E
\end{aligned}
$$

where $E=\max \left\{\left(I+T+M+\phi B e^{-r}-(1+\pi) B e^{-r}-W\right), 0\right\}$,

and

$$
I=\sum_{\forall j \in L} I_{j}, \quad j_{L 0}=\sum_{\forall j \in L} j_{L_{j} 0}
$$

The components of shareholder value follow: $j_{L 0}-I$ is the net present value of the bank's loan portfolio; $e^{-r} J$ is the present value of the bank's end-of-period franchise value; $B e^{-r} \pi$ is deposit-generated fee income; and $P_{I}-\phi B e^{-r}$ is the value of the deposit insurance guarantee net of the premium paid. $P_{I}$, the gross value of the insurance guarantee, has a value equivalent to that of a simple European put option written on the bank's total asset portfolio with a strike price of $j_{d}=$ $B-T e^{r}-\left(1-d_{1}\right) J{ }^{12}$ This strike price is the cash flow value below which the bank's shareholders find it optimal to default on the bank's deposit liabilities. For $j_{d} \leq 0$, $P_{I} \equiv 0$.

The second line in expression (3) captures the costs associated with outside equity issuance. $E$ is the financing gap that remains after deposits and inside equity are exhausted by the bank's investments. Each dollar of external finance requires that $\frac{1}{1-d_{0}}$ dollars of outside equity be raised as each dollar of outside equity generates $d_{0}$ in issuance costs. $\frac{d_{1}}{1-d_{1}}\left(P_{I}-P_{D}\right)$ is the initial value of the contingent liability generated by end-of-period distress costs. The distress costs are proportional to the difference

\footnotetext{
${ }^{11} \mathrm{~A}$ derivation is given in the appendix.

${ }^{12}$ If the asset portfolio's value is lognormal, the option is valued using Black Scholes.
} 
between two simple put options, $P_{I}$ and $P_{D}$, where both options are defined on the underlying value of the bank's asset portfolio. $P_{D}$ is the value of a put option with a strike price of $j_{d s}=B-T e^{r}$, the threshold value below which the bank must raise outside equity to avoid default. The strike prices of these options define the range of cash-flow realizations, $\left(j_{d}, j_{d s}\right)$, within which shareholders bear financial distress costs. ${ }^{13}$ Distress costs reduce shareholder value since $P_{I} \leq P_{D}$.

\section{Bank Shareholder Value Under the PCA}

Under the PCA, the bank must establish its market risk pre-commitment. The bank's pre-commitment is its market risk capital requirement and, in the absence of other capital requirements, establishes the minimum required equity investment in the bank. The bank will be assessed a penalty if its subsequent trading account losses exceed its market risk pre-commitment.

In this model, the trading account is equivalent to the bank's risky market-traded securities portfolio. Let $C V$ represent the bank's pre-commitment. If the bank's trading account activities subsequently generate a loss that exceeds $C V$, we assume that the bank will pay an ex post deposit insurance premium of $\Upsilon$ per-dollar of excess loss if it remains solvent. Formally, the contingent insurance premium is given by,

$$
\Upsilon \max \left\{\left(C-j_{M 1}\right), 0\right\},
$$

where $\quad C \equiv M-C V ; \quad C V \geq 0$.

The parameter $C$ sets a threshold level for the end-of-period value on the bank's risky securities portfolio, $j_{M 1}$, below which there is an ex post premium obligation.

The imposition of the PCA alters the shareholder value equation. Under the

$13 \frac{d_{1}}{1-d_{1}} P_{D}$ is the risk-adjusted present value of the distress costs the bank would face in the absence of deposit insurance. Because of deposit insurance, bank shareholders will not have to bear distress costs for portfolio value realizations less than $j_{d}$, the default threshold. In default states, distress costs transfer to the deposit insurer. $\frac{d_{1}}{1-d_{1}} P_{I}$ appearing in the shareholder distress costs term credits shareholders with the default portion of the distress costs. 
assumed penalty structure, the bank's shareholder value becomes ${ }^{14}$

$$
\begin{aligned}
S & =j_{L 0}-I+e^{-r} J+B e^{-r} \pi+P_{I}^{\prime}-\Upsilon P_{C}-\phi B e^{-r} \\
& -\frac{d_{0}}{1-d_{0}} E+\frac{d_{1}}{1-d_{1}}\left(P_{I}^{\prime}-P_{D}^{\prime}\right)
\end{aligned}
$$

where $P_{I}^{\prime}-\Upsilon P_{C}-\phi B e^{-r}$ now represents the net value of the implicit deposit insurance guarantee, and $\frac{d_{1}}{1-d_{1}}\left(P_{I}^{\prime}-P_{D}^{\prime}\right)$ is the net risk-adjusted present value of potential distress costs under the PCA. Among its other effects, the PCA saddles bank shareholders with a short position of $\Upsilon$ put options written on the value of the bank's risky securities portfolio. This put option, $P_{C}$, has a strike price $C$ that is determined in part by the magnitude of the bank's pre-commitment.

The PCA also alters the gross deposit insurance value $\left(P_{I}^{\prime}\right)$ and the value of distress issuance costs $\frac{d_{1}}{1-d_{1}}\left(P_{I}^{\prime}-P_{D}^{\prime}\right)$. PCA increases the costs of financial distress by increasing the likelihood that the bank will have to issue outside equity to avoid default. ${ }^{15}$ Off-setting the higher distress cost is an implicit rebate on the contingent pre-commitment penalty when the bank defaults. The offset arises because the regulator cannot enforce the pre-commitment payment in insolvency states. This adds value to the implicit deposit insurance option $\left(P_{I}^{\prime}>P_{I}\right)$ compared to the baseline case of $\Upsilon=0$ for which shareholder value takes the earlier form in expression (3).

Because the PCA penalty structure alters the form of the insurance and distress cost options, these options no longer have simple put option payoff structures. Under PCA, both $P_{I}^{\prime}$ and $P_{D}^{\prime}$ have payoff values that are determined by functions of multiple stochastic processes. As such, they are exotic options whose valuations require the use of numerical techniques. Explicit expressions for these option payoffs are derived and valuation issues are concretely discussed in the appendix.

\footnotetext{
${ }^{14} \mathrm{~A}$ derivation of this expression is given in the appendix.

${ }^{15} \mathrm{~A}$ pre-commitment fine increases the strike price of the distress cost put option.
} 


\section{Shareholder Value Maximization}

Under the assumptions of this model, the shareholder value function, $S$, must be optimized using integer programming methods. The necessity of the programming approach owes to the assumption that loans are discrete non-tradeable investments with individualized risk and return characteristics.

Let $j_{L_{k} 0}$ represent the risk-adjusted present value of loan portfolio $k$ that can be formed from the bank's loan investment opportunity set. The loan portfolio has a required investment of $I_{k}$ and an NPV equal to $j_{L_{k} 0}-I_{k}$. The bank shareholder maximization problem can be written as,

$$
\max S=e^{-r} J+\max _{\forall k}\left\{\left(j_{L_{k} 0}-I_{k}\right)+\max \left\{\left.\operatorname{SNB}\left(j_{L_{j}}\right)\right|_{L_{j}=L_{k}}\right\}\right\}
$$

where

$$
\operatorname{SNB}\left(j_{L_{j}}\right)=P_{I}^{\prime}-\Upsilon P_{C}+(\pi-\phi) B e^{-r}-\frac{d_{0}}{1-d_{0}} E+\frac{d_{1}}{1-d_{1}}\left(P_{I}^{\prime}-P_{D}^{\prime}\right)
$$

and $\left.\operatorname{SNB}\left(j_{L_{j}}\right)\right|_{L_{j}=L_{k}}$ indicates that the SNB function is to be evaluated conditional on the loan portfolio $L_{k}$. The conditional value of the SNB function is maximized over $T, M, B, W, C V$, and the risk characteristics of the market-traded securities portfolio subject to the financing constraint

$$
I+T+M-B e^{-r}(1+\pi-\phi)-W-E=0
$$

while imposing $B \in(0, \bar{B})$ and $I, T, M, B, W, E, C V \geq 0, W+E \geq C V$. Thus, for each possible loan portfolio within the bank's loan opportunity set, the bank maximizes the portfolio's associated SNB value by making the appropriate investment choices for risk-free and risky securities, outside equity issuance, and inside capital (or dividend pay-out policy). The bank chooses the loan portfolio for which the sum of loan portfolio NPV and associated maximum SNB value is the greatest.

Under the assumptions of this model, even in the absence of PCA, optimal loan investment decisions will in general depend not only on loan NPVs, but also on their 
risk exposure characteristics and their financing requirements. As a general rule, the optimal loan portfolio - the loan portfolio that maximizes shareholder value - will not include all positive NPV loans.

\section{Bank Behavior with Perfect Access to Capital Markets}

The bank optimization problem outlined in the prior section differs significantly from the marginal analysis approach used in many economic models. The lack of any theoretical relationship between a loan's NPV and its risk characteristics prohibits specializing the optimization program by formulating a marginal efficiency of investment schedule. Further, any scheme for sorting among alternative loan portfolios will depend on whether or not the bank is attempting to exploit the value of its deposit insurance guarantee. A priori, even without equity issuance costs there is no unique way to rank a bank's loan alternatives in order to simplify the analysis. ${ }^{16}$

The central importance of an individual bank's loan opportunity set is more clearly identified if the model is specialized to remove all capital market imperfections. ${ }^{17}$ In this section, a bank's optimal behavior under FRI and the consequences of the PCA are analyzed under the assumptions that the bank has costless access to equity financing, both in the initial period, $d_{0}=0$, and in the case of financial distress, $d_{1}=0$. In addition, the bank is assumed to have unrestricted investment access to risk-free and infinitely risky market-traded securities. This special case is instructive in that, even though the bank has unencumbered access to extreme market risk strategies, its optimal decisions will depend on the NPV and risk characteristics of its loan investment opportunity set. Moreover, the efficacy of the PCA will also depend

\footnotetext{
${ }^{16}$ For example, a bank attempting to minimize its risk of default may rank loans by solving something analogous to an efficient frontier problem for loan portfolios; that is, for any level of loan portfolio NPV, it would identify the set of loans that satisfy the NPV requirement with minimum risk. In contrast, for a bank attempting to exploit its deposit insurance guarantee, the bank might want to sort loans according to a mirror image algorithm: for each possible loan portfolio NPV, choose the set of loans that achieves the NPV with maximum total risk.

${ }^{17}$ We maintain the assumption that loans are discrete non-traded assets.
} 
on the characteristics of the bank's loan investment opportunity set.

Proposition 1 If (i) equity issuance costs are zero $\left(d_{0}=0, d_{1}=0\right)$; and the bank has (ii) unrestricted access to risk-free bond investments; and (iii) unrestricted access to zero-NPV securities with unbounded risk exposure; then the risk characteristics of a bank's optimal investment strategy will depend on the bank's franchise value and the characteristics of the bank's loan investment opportunity set. ${ }^{18}$

Proposition 1 establishes the central importance of the bank's loan opportunity set in the design of bank regulatory policy. That is, without knowledge of the characteristics of the bank's loan opportunity set, it is not possible to determine a priori a bank's optimal risk exposure and thus the default risk the bank will create for the BIF. The optimal risk profile of a bank will depend critically on the relationship between NPV and risk that is inherent in a bank's individual loan opportunity set. Because loans are non-tradeable, each bank will face a different loan opportunity set. ${ }^{19}$ Indeed, it is only when loans are redundant assets (from the bank's point of view) that the characteristics of the loan opportunity set are not determinants of the bank's optimal default risk exposure.

Corollary 1 Under the capital market access conditions of Proposition 1, if all loans in a bank's investment opportunity set have $N P V \leq 0$, then a bank's optimal strategy and risk profile are independent of the characteristics of its loan investment opportunity set.

Under the conditions of Corollary 1, since the bank gets no shareholder value from loans themselves, it will maximize shareholder value by maximizing its SNB

\footnotetext{
${ }^{18}$ All Propositions and Corollaries are proved in the Appendix.

${ }^{19} \mathrm{In}$ reality, there is a burgeoning secondary market in bank loan portfolios. Such loan trading does not invalidate the importance of an individual bank's loan origination investment opportunity set for it is at the origination level that a bank will capture the economic value of a loan. Loans traded on a competitive secondary market will by necessity trade at prices that ensure that they are 0 NPV investments.
} 
value. Assuming that the profits from supplying deposit services net of the insurance premium are positive, the proof of Corollary 1 shows that the bank will maximize its SNB value by either choosing to be free of default risk or by undertaking a "gofor-broke" high-risk strategy. The value of a bank's optimal risk-free strategy is independent of the characteristics of the bank's loan opportunity set if and only if its loan opportunities have NPV $\leq 0$. Similarly, when all bank loan opportunities have NPV $\leq 0$, an optimal go-for-broke strategy will use only risky market-traded securities to maximize the value of the deposit insurance guarantee. This corollary highlights the importance of modeling loans as positive NPV investments. If loans do not offer banks positive NPV investment alternatives, then there is nothing special about the bank lending function that will shape a bank's choice of its optimal risk exposure profile.

Consider the implications of introducing the PCA when banks have perfect access to capital markets.

Proposition 2 Under the conditions of Proposition 1, a PCA can only be effective if a bank's loan investment opportunity set includes positive NPV loan opportunities.

Presuming that go-for-broke is a viable bank strategy, if the bank does not have positive NPV loan opportunities, then a PCA cannot deter bank incentives to take excess market risk. Absent positive NPV loan alternatives, a bank will either choose to be free of default risk, or adopt an optimal go-for-broke strategy. Because a safe bank will fully-collateralize its deposits with risk-free bonds, its deposit insurance is valueless, and the bank has no incentive to take 0 NPV market risks. Moreover, if a bank following a safe strategy did take market risk, the bank could costlessly precommit $M$ and avoid any pre-commitment penalty since, by assumption, it is costless to raise equity capital. Hence a safe bank's contingent ex post penalty will always be zero and the PCA will not affect its share value. Indeed under the conditions of Proposition 1, no form of regulatory capital requirement will have an effect on 
the share value of a bank following a safe strategy as capital requirements could be met costlessly by raising equity capital and investing the additional funds in 0 NPV investments.

Similarly, under the perfect capital market access conditions of Proposition 1 the share value of a bank that forgoes making loan investments and instead adopts a go-for-broke strategy using 0 NPV market-traded securities is undisturbed by the introduction of the PCA. Because the bank can purchase market-traded securities with unbounded risk, the go-for-broke strategy generates the asymptotic value of its deposit insurance guarantee, $\bar{B} e^{-r}-J e^{-r}$, a value that is independent of the existence of any PCA penalties. To see this note that the magnitude of the PCA penalty rate determines the rate at which the bank pays a penalty for market risk losses in excess of its pre-commitment provided it does not default. If the bank takes all market risk, its pre-commitment fine is bounded by $J e^{-r}$, the loss the bank foregoes when it defaults. Since the pre-commitment fine rate cannot increase the magnitude or probability of incurring this maximum loss, the PCA does not diminish the bank's deposit insurance value. Thus the adoption of the PCA will not effect the share value or alter the behavior of such a bank.

The converse of Proposition 2 is that, under the perfect capital market access conditions of Proposition 1, the PCA can only be effective if the bank has positive NPV loan opportunities. For the PCA to be effective, it has to dissuade a bank from taking market risk to exploit its deposit insurance guarantee. For this to be possible, a bank's unregulated investment strategy must generate an insurance value less than the bank's asymptotic deposit insurance value, for only then can the adoption of the PCA affect shareholder value. If a bank's loan investment opportunity set includes positive NPV loan opportunities, it is possible that the adoption of a profitable positive loan investment strategy may preclude a bank from maximizing the value of its deposit insurance guarantee even if it has access to market-traded securities with unbounded risk. The bank may find such a strategy to be optimal provided that the 
loan investment adds NPV that exceeds the diminution in the value of the bank's deposit insurance guarantee (as compared to its asymptotic value). In such a case, the PCA can be effective in deterring a bank from using market risk to enhance the value of its insurance guarantee. ${ }^{20}$

\section{Behavior when Access to Capital Markets is Imperfect}

The prior analysis indicates that the efficacy of the PCA depends fundamentally on the characteristics of banks' loan investment opportunity sets. Although the propositions and corollaries of the prior section are of theoretical interest, the capital market access conditions that underlie these results are clearly not satisfied in practice.

When it is costly to raise external equity capital or when a bank's ability to take on market risk is limited, a bank may no longer be able to afford a completely default risk-free strategy or be able to obtain a high-risk strategy that generates an asymptotic insurance value. As a consequence, the existence of capital market imperfections can enhance the effectiveness of the PCA.

When a realistic complement of capital market imperfections are introduced, optimal bank strategies with and without the PCA must be analyzed at the microeconomic level of detail. Although the limitations inherent in examining specific cases must be recognized, we analyze the effectiveness of the PCA for banks facing different loan investment opportunity set characteristics but identical securities market investment opportunities, financing costs, and franchise values. This analysis provides some perspective on the potential efficacy of the PCA under more realistic capital market access conditions while recognizing the bank-specific nature of loan investment opportunity sets.

\footnotetext{
${ }^{20}$ Among alternative regulatory capital regimes, the ineffectiveness of the PCA under the capital market access conditions of Proposition 1 is not unique. If a bank has access to securities market investments with unbounded risk and the ability to raise equity capital costlessly, a regulatory maximum leverage constraint may also be ineffective in limiting a bank's ability to exploit the deposit insurance guarantee for the same reasons that render the PCA ineffective.
} 
Three alternative loan investment opportunity sets depicting different possible loan NPV and risk combinations are described in Table 1. Individual loan NPVs are calculated assuming a single systematic risk factor, a default-free rate of interest of .05, and a lognormal distribution for the end-of-period values of each loan. ${ }^{21}$ The alternative loan opportunity sets include loans with differing investment requirements, risk, and NPV characteristics. Loan opportunity set A includes loans with relatively modest overall risk. Loan opportunity set B includes two relatively high risk loan alternatives one of which has a substantial NPV relative to its required investment. Although loan opportunity set $\mathrm{C}$ also includes a set of relatively high risk loans, the single most profitable loan in set $\mathrm{C}$ is distinguished by its negative systematic risk. The bank can also purchase risk-free bonds and a 0 NPV, risky market-traded securities portfolio (the risky security) in any desired amount subject to meeting its financing constraint. The risk and return characteristics of the risky security are summarized in the last row of Table 1.

Several regulatory constraints also are imposed independent of the PCA. One is that the bank cannot start the initial period with negative book capital. Further, it can be optimal for a bank to forego making any loans and invest all deposits in risky securities. Assuming that the regulator can observe the bank's investment in risky 0 NPV securities, any such investment strategy will signal the bank has no value beyond its deposit insurance guarantee. Such an operating policy is prohibited. In a subsequent section, the possibility that a bank's market-traded securities positions may generate positive economic profits from income earned from market-making services is introduced. In this extension we revisit the issue of market risk exposure concentration in banks and the viability of the PCA in such an environment.

Other specific parameter assumptions are: (1) the maximum amount of insured deposits is $\bar{B}=200$; (2) the fixed deposit insurance premium rate is $\phi=.01$; (3) the fixed profit rate on deposits is $\pi=.025$; (4) per-dollar equity issuance costs are

\footnotetext{
${ }^{21}$ The systematic risk factor is assumed to have a market price of 1 .
} 
$d_{0}=.2 ;(5)$ end-of-period distress costs are $d_{1}=.4$ per dollar of equity issuance; and (6) the bank's franchise value is $J=40$. The bank's internal equity finance is subject to the constraint $0 \leq W \leq 27$.

The bank's alternative operating strategies are described by the individual rows in Table 2. The rows in the table correspond to the alternative loan portfolios that are feasible under each loan opportunity set given the bank's financing constraint. Columns 1 and 2 report the positions in risky $(M)$ and risk-free $(T)$ bonds that maximize net shareholder value $(S)$ for the loan portfolio described by the investment amounts in columns 3 through 5 . Column $6(W)$ reports the value-maximizing amounts of internal equity finance; column 7 (share value) reports the maximum net share values for the respective loan portfolios; and column $8\left(P_{I}\right)$ reports the present values of the deposit insurance guarantee gross of the fixed premium payment of 1.93. ${ }^{22}$ The values reported in these 3 columns are based on the assumption of no capital requirements other than a non-negative minimum book equity constraint. The final 6 columns in the table report the maximum shareholder values and corresponding net values of the insurance guarantee (gross of the fixed premium payment) for each alternative loan portfolio under a PCA capital requirement with penalty rates of $1(\mathrm{PCA}(1)), 2(\mathrm{PCA}(2))$, and $3(\mathrm{PCA}(3)) \cdot{ }^{23}$

\subsection{Optimality of bank decisions without a PCA}

Optimality conditions are defined by the capital and investment settings that generate the largest possible share value (Table 2, column 7) among the permissible strategies under the the assumed loan opportunity set and market-traded security investment opportunity. Globally optimal bank strategies and their associated deposit insurance

\footnotetext{
${ }^{22}$ In these examples, all banks accept their maximum feasible insured deposit base of $\$ 200$.

${ }^{23}$ Optimizing values for the choice variables, maximum shareholder values, and the associated values for deposit insurance are determined using numerical methods. Specifically, asset and option values are calculated using monte carlo simulation and the numerical equivalent martingale valuation techniques suggested by Duan and Siminto (1995).
} 
guarantee values are identified by boldface type.

In the absence of capital regulation, it is optimal for a bank facing loan opportunity set $\mathrm{A}$ to retain 27 in inside equity capital and invest in all of the loans in its investment opportunity set. This strategy generates a total share value of 57.47 and a deposit insurance value of 0.37 gross of the 1.93 initial premium payment. ${ }^{24}$ Under this investment opportunity set the bank invests in all positive NPV loan opportunities. This investment strategy generates little risk for the BIF-indeed the bank's fixed deposit insurance premium exceeds the value of its insurance guarantee.

Under loan opportunity set B, a bank finds it optimal to pay out all inside equity capital as dividends, invest in loans 1 and 3, and invest 68 in the risky security. Such a strategy generates a share value of 59.09 and an insurance value of 9.41 gross of the 1.93 initial premium. Under loan opportunity set B, the bank forgoes a low-risk positive NPV loan (loan 2) because a competing use of scarce investment funds (the risky security) generates a larger increment in shareholder value by increasing bank risk and the value of the deposit insurance guarantee.

For a bank facing loan opportunity set $\mathrm{C}$, absent PCA, it is optimal to pay out all inside equity capital as dividends, invest in loans 1 and 2, and invest 18 in the risky security. This generates a share value of 53.52. The bank avoids investing in the positive NPV loan 3 and holds no risk-free bonds. Although the bank could have taken a modest position in the risky security to hedge the systematic risk of loan 2 , instead it prefers a large position that increases its asset portfolio risk and insurance value.

\subsection{Effects of a PCA on optimal bank decisions}

The columns in Table 2 labeled, "net share value under PCA," (columns 9-11) report maximum share values obtainable under a PCA with the indicated pre-commitment

\footnotetext{
${ }^{24}$ The bank's profits from service fees exceed the deposit insurance costs so the bank still finds it profitable to accept insured deposits.
} 
penalty rate using the row-specific loan portfolio. A superscripted share value entry indicates that the imposition of the PCA induces the bank to alter its optimal investment strategy from its unregulated optimum to one that includes no exposure to the risky security. The columns labeled, " $P_{I}^{\prime}-\Upsilon P_{C}$ under PCA," (Table 2, columns 12-14) report the values of the bank's deposit insurance guarantee, gross of the initial premium, under the indicated PCA fine rates.

Loan opportunity set $A$

Initially, we consider the affects of the PCA on the bank's alternative investment strategies. Absent the PCA, 4 of the 7 possible loan portfolios under opportunity set A admit optimal strategies with 0 inside equity capital and significant positions in the risky security. The application of the $\mathrm{PCA}$ with a fine rate of $1(\mathrm{PCA}(1))$ removes the incentive to invest in the risky security in 3 of the 4 high-risk strategies. The only case that does not respond to the PCA for any of the illustrated fine rates is a strategy that involves a minimal investment (50) in a low NPV loan, and a significant position (143) in the risky security.

Under loan opportunity set A, however, the unregulated globally optimal bank portfolio contains no market risk. Thus, the adoption of the PCA does not alter the optimal investment strategy. The bank finds it optimal to continue to retain 27 of inside equity capital, raise no outside capital, invest in all three loans, and pre-commit zero $(C V=0)$. The imposition of the PCA has no consequences in this case.

\section{Loan opportunity set $B$}

Without the PCA, 4 of the 7 feasible loan portfolios under opportunity set B are associated with a high-risk strategy of holding 0 inside equity capital and purchasing the risky security. $\mathrm{PCA}(1)$ is not sufficient to remove the risk-taking incentives for any of these alternative loan portfolios, although in each case the values of the insurance guarantee are reduced. If the PCA penalty rate is increased to 2 , for 2 of the 4 loan portfolios it is no longer optimal for the bank to take a position in the risky security. 
Under a PCA penalty of 3, for only one of the possible loan portfolios does a risky securities position remain optimal.

Under PCA(1), although the bank's globally optimal investment and financing decisions remain unchanged from the unregulated optimum, the PCA does lower the insurance value to 6.04. Modest PCA penalty rates are ineffective when a bank's unregulated risk exposure profile is heavily skewed toward market risk. However, if the PCA penalty rate is increased to 2, the bank's globally optimally strategy is altered. Its new optimal strategy is to hold no risky securities and pre-commit zero $(C V=0)$, retain 27 in inside equity capital, invest in loans 1 and 2 instead of loans 1 and 3, and purchase 5 in risk free bonds. The net value of the bank's deposit insurance guarantee drops from 9.41 without regulation to 1.15 with PCA (against an insurance premium of 1.93). The PCA lowers its maximum share value to $52.70 .{ }^{25}$

Loan opportunity set $C$

Absent PCA, 6 of the 7 feasible loan portfolios under opportunity set $\mathrm{C}$ require zero equity capital and positive market risk to generate maximum share value. The imposition of PCA(1) removes the incentive to take market risk and induces the bank to retain maximum inside equity of 27 in 3 of the 6 cases. Under PCA(2), the risk incentives are removed for 4 of the 6 portfolios. The two remaining risky strategies are unaffected by PCA penalty rates as high as 3 . Again, this example illustrates that modest PCA penalty rates are ineffective when a bank's unregulated risk exposure profile is heavily skewed toward market risk.

A PCA of 1, nonetheless, is sufficient to mute the bank's risk-taking incentives under loan opportunity set C. Without the PCA, the global optimal strategy required the bank to pay out all inside equity, invest in loans 1 and 2, and take a position in the risky security. Under PCA(1), the globally optimal strategy requires the bank to retain maximum inside equity of 27 , raise outside equity of 5 , hold no risky securities

\footnotetext{
${ }^{25}$ While the insurance premium exceeds the insurance value, the bank still realizes a net profit on deposits.
} 
(pre-commit zero), and add positive NPV loan 3 to its portfolio. The bank's insurance value is lowered from 5.74 to 1.54 .

\section{Summary}

These illustrations suggest several conclusions on the effectiveness of the PCA. With a sufficiently high penalty rate, a PCA can discourage a bank from taking market risk exposure in order to exploit its insurance guarantee. If, however, a bank's unregulated optimal loan portfolio requires only a modest investment relative to the bank's insured deposits, a PCA may not discourage a bank from taking market risk exposure if the bank has the opportunity to invest in securities with substantial risk. A modest PCA penalty rate does not sufficiently diminish the reward to risk taking and, while higher penalty rates are more effective, the increased effectiveness diminishes as the penalty rate is raised further. Although the PCA may be unable to completely remove bank incentives to exploit the BIF using trading account risk, it consistently creates the correct incentives by reducing the value bank shareholders gain from investing in $0 \mathrm{NPV}$ risky securities. Even when it does not alter risk-taking behavior, the PCA reduces the insurer's ex ante liability. Moreover, the PCA imposes little or no cost on banks with minimal market risk exposures.

The results also suggest that, besides altering market risk incentives, the PCA may affect a bank's optimal loan portfolio and its optimal capital or leverage ratio. Under loan opportunity sets $\mathrm{B}$ and $\mathrm{C}$, the PCA resulted in new loan portfolios with higher NPVs and, under opportunity set B, lower loan risk. Because equity finance is costly, absent PCA, some positive NPV loans may be foregone in order to invest in a high risk 0 NPV market security to enhance the insurance value. By reducing incentives to take market risk with $0 \mathrm{NPV}$ securities, the PCA may increase investment in positive NPV loans. Also, by reducing the ability to profit from market risk exposure, the PCA can encourage the bank to take a globally safer strategy. For instance, under opportunity set B, PCA(2) increased the optimal level of the bank's equity capital and reduced its loan portfolio risk. 
While these illustrations show potential bank-wide benefits of the PCA, other loan investment opportunities can be constructed for which the adoption of a PCA can lead simply to substitution of loan risk for market risk in the trading account. A trivial example is if there is a 0 NPV loan whose risk characteristics match those of the risky security. Without the PCA, under an optimal high risk strategy, a bank might be indifferent between investment in the 0 NPV risky loan and the risky security. If the latter is chosen, imposition of a PCA would simply cause the bank to shift its investment to the 0 NPV risky loan without affecting its optimal all-in risk or its insurance value. This weakness is not confined to the PCA but is inherent in all piecemeal approaches to capital regulation.

\subsection{Aggregate effects of a PCA}

Although the efficacy of a PCA will be sensitive to the characteristics of individual bank's investment opportunity sets, it is instructive to consider the aggregate effects of a PCA using loan opportunity sets A, B and C. Consider the following population of 12 banks. Three banks each face a different individual loan opportunity set, A, B, or $\mathrm{C}$. The remaining 9 banks each face a unique loan opportunity set that consists of the 9 pairwise loan combinations taken from opportunity set A, B, or C. Individual bank loan opportunity sets are enumerated in column 1 of Table 3 where A1 indicates loan 1 from opportunity set A and so on. Except for different loan opportunity sets, all banks have the same exogenous parameter values used in the prior examples.

The row entries in the second and third column of Table 3 report, respectively, individual banks' optimal share values and the corresponding values of their deposit insurance guarantee gross of the initial premium. Similar entries in the remaining columns report bank's optimal share and insurance values under a PCA with the indicated penalty rate. The final row in Table 3 records the total subsidy granted this hypothetical banking system owing to under-priced deposit insurance.

In the absence of any capital regulations, the hypothetical banking system would 
generate 651.72 in aggregate bank share value including a deposit insurance subsidy of 69.01. A majority of the banks in the system pursue a high-risk strategy that includes positions in the risky market securities portfolio. The imposition of $\mathrm{PCA}(1)$ reduces market risk-taking in a majority of the banks that otherwise preferred a risky strategy. The aggregate value of deposit insurance subsidy falls by 47.77 , a reduction of more than half the unregulated subsidy value. The reduction in the aggregate deposit insurance subsidy is not reflected one-for-one in aggregate bank share values as share values fall by only 22.07 , a reduction of less than 4 percent of unregulated share value. Share value reductions are tempered by the changes in bank behavior engendered by the PCA. When the PCA is introduced, banks adopt safer market risk investment strategies - they switch out of risky securities and into risk free bond investments. This change in strategy reduces banks' expected costs of financial distress, a gain that partly offsets the reduction in their deposit insurance subsidy. In addition to the changes in banks' market risk investment strategies, PCA also tends to encourage lower leverage ratios (greater overall bank capital) and altered loan investment strategies. In some instances, banks will substitute positive net present value loan investments for the $0 \mathrm{NPV}$ market risk exposures they preferred in the absence of PCA. This additional positive NPV investment is a second source of value that tempers the PCA-related loss in banks' aggregate insurance subsidy.

As the PCA penalty rate is increased, the aggregate insurance subsidy continues to decrease, but at a decreasing rate. An increase in the penalty to 2 reduces the aggregate subsidy by 10.58 and a further increase to 3 reduces the subsidy by only 0.77. Increases in the PCA penalty rate also have diminishing effects on the aggregate value of bank shares. The penalty rate increase from 1 to 2 reduces aggregate equity values by less than 3 (less than one-half percent) and an additional dollar increase diminishes equity prices by only about 1 in aggregate.

Overall, the results in Table 3 show that PCA generates substantial reductions in BIF risk and the aggregate insurance subsidy. For most banks in this example, the 
values of the insurance guarantee (net of the PCA contingent penalty) are uniformly small and below their premiums. For this majority, the up-front flat rate premium could be lowered and thereby move FRI toward a fair-pricing basis. However, a minority of banks - those for whom the PCA is ineffective-still enjoy substantial insurance subsidies. This suggests that, even when the PCA is an effective policy on a bank aggregate basis, for some banks it will be inadequate. These banks will require more direct regulation of their trading activities.

\section{PCA When Market Risk Can Create Economic Profits}

Thus far, consistent with absence of arbitrage equilibrium conditions, we have maintained the assumption that market-traded financial assets are 0 NPV investments. In reality, although banks' proprietary market-traded positions are objectively $0 \mathrm{NPV}$ investments, banks appear to consistently generate economic profits from providing dealer and market-making services for many types of financial instruments. Although the ability to generate true economic profits from market-making activities is inconsistent with the equilibrium conditions of any frictionless no-arbitrage model, nonetheless market-making activities are profit centers for most money-center banks. This reality is at odds with the banking model developed thus far as the model only admits 0 NPV investment opportunities in market-traded securities. A consequence of the model's assumption is that, unless a bank is hedging a loan with negative systematic risk, a bank taking market risk exposure is attempting to exploit its deposit insurance guarantee. In this section we generalize the model so that a risk exposure profile that is dominated by market risk may not be premia facia evidence that a bank is following a go-for-broke strategy.

In addition to positive NPV loan investment opportunities and 0 NPV markettraded security investments, assume that the bank has the opportunity to invest in a market-making operation for some set of traded instruments. While it is important to consider the effects of a PCA in an environment where market risks can generate 
economic profits, the direct modeling of market-making activities introduces serious complications: (1) short positions and derivative contracts introduce credit risks that are not easily modeled; and (2) it is unclear how a rigorous model of market-making can produce positive NPV cash flows in a model where a market-maker's book is composed of assets that satisfy no-arbitrage equilibrium conditions.

\subsection{A positive NPV market-making activity}

From the standpoint of analyzing the PCA, we can incorporate the important features of market-making without attempting to fully account for its micro-economic details. We abstract away from the details of a market-making operation and assume that this activity requires a positive investment and exposes the bank to systematic and idiosyncratic risks. ${ }^{26}$ We assume that market-making requires an initial investment of $\mathcal{M}$, and generates an end-of-period cash flow,

$$
j_{\mathcal{M} 1}=\mathcal{M} e^{\mu_{\mathcal{M}}+s_{\mathcal{M}} z_{1}}
$$

Under these assumptions, a bank's total market risk exposure will be the sum of the risk exposure generated by its proprietary trading positions (represented by an investment $M$ and an associated stochastic end-of-period value $j_{M 1}$ ), and risk exposures generated through its market-making activities (represented by an investment $\mathcal{M}$ and a stochastic end-of-period value $\left.j_{\mathcal{M} 1}\right) .{ }^{27}$ As PCA applies to a bank's entire market risk exposure, the PCA penalty schedule is given by,

$$
\Upsilon \max \left\{\left(C-\left(j_{M 1}+j_{\mathcal{M} 1}\right), 0\right\}\right.
$$

\footnotetext{
${ }^{26}$ A book that is approximately balanced or "matched" would require little or no initial investment were it not for credit risk and asymmetric information. Because of these complications, even a matched-book will require a positive investment to satisfy explicit counterparty collateralization requirements or to satisfy implicit competitive market-generated capital requirements that arise from counterparty pressures to ensure contract performance.

${ }^{27}$ In this one-period model, $j_{\mathcal{M} 1}$ will include the net value of positions in the market-making book and the cash flows generated from market-making profits. In reality, market-making is a long-lived activity and so $j_{\mathcal{M} 1}$ will also include the NPV of all future anticipated market-making profits.
} 


$$
C \equiv(M+\mathcal{M})-C V ; \quad C V \geq 0
$$

After including the NPV of market-making activities, $\left(j_{\mathcal{M} 1}-\mathcal{M}\right)$, and substituting $\left(j_{M 1}+j_{\mathcal{M} 1}\right)$ in place of $j_{M 1}$ to account for the new source of market risk, valuation expressions (5) and (6) directly generalize to accommodate positive NPV marketmaking activities.

\subsection{Optimal bank behavior}

As modeled, the market-making activity is, aside from its treatment under the PCA, analogous to a positive NPV loan investment opportunity. Although it is possible to revisit the analysis under the unrestricted capital market access conditions of Proposition 1, little intuition would be gained relative to difficulty of including the positive market-making activity into the formal propositions. ${ }^{28}$ Thus we consider the implications of adding the market-making investment opportunity in the context of a specific loan investment opportunity set when access to capital markets is imperfect.

Consider a bank that faces loan opportunity set $\mathrm{C}$ in Table 1 and model parameters identical to those that underlie the examples reported in Table 2. In addition to the opportunity to invest in the 0 NPV risky market-traded security described in Table 1 , assume that the bank's opportunity set is augmented with the opportunity to invest in a market-making operation. The activity has an expected return of 0.2 , systematic risk of 0.05 , idiosyncratic risk of 0.35 and total (standard deviation) risk of 0.354 . This new investment activity requires an initial investment of 75 and produces an expected NPV of 7.89 using the valuation method in expression (2). The rows in Table 4 report vital statistics on the individual portfolios that are feasible for a bank

\footnotetext{
${ }^{28}$ The omitted formal proposition would state that: for PCA to be effective, a necessary condition is that a bank must either have positive NPV loan or market-making opportunities (or both). The difficulty in formally establishing this proposition involves the proof of limiting option values. Although the necessary limits can be verified numerically, their formal proof is mathematically daunting owing to the analytical intractability of the distribution function of the sums three or more lognormal variables.
} 
facing this investment opportunity set.

Columns 1 and 3 in Table 4 report the combinations of the 0 NPV risky security (M), and the risk free bond (T) that are optimal given the particular set of investments in market-making $(\mathcal{M})$ and loan opportunities recorded in columns $2,4,5$ and 6 . The total investment in the bank's trading account is given by the sum $(M+\mathcal{M})$. Column 7 (W) records the optimal amount of inside equity capital financing associated with each row-specific strategy. The entries in the "share value" and " $P_{I}$ " columns record each strategy's maximum share value and the associated value of the deposit insurance guarantee that is generated in the absence of any capital regulations. Columns labeled "net share values under PCA" record the optimal share values that can be generated given each row's positive-NPV investment settings under the designated PCA penalty rate. The final three columns record, for each PCA penalty rate, the optimal precommitment amount $(\mathrm{CV})$ and the value of the bank's insurance guarantee gross of its initial premium payments $\left(P_{I}^{\prime}-\Upsilon P_{C}\right)$.

Consider initially the effects of a PCA on the individual investment strategies feasible under this investment opportunity set. In 7 of the 15 cases, absent PCA, the bank uses the risky 0 NPV security to increase share value. In all of these cases, a PCA is effective in reducing the value of the bank's deposit insurance guarantee. In 5 of the 7 cases, the adoption of PCA(1) causes the bank to cease investing in the 0 NPV risky market-traded security. In 2 of these 5 cases, there is also investment in the market-making activity, but this is not affected by the PCA. When the PCA discourages investments in the 0 NPV risky security, it also induces the bank to retain 27 in equity capital. This capital is pre-committed if the bank is undertaking the market-making activity. In cases in which the bank has significant positive market risk exposure but no position in the 0 NPV risky security, market risk arises from the positive NPV market-making activities, not from following a high-risk strategy. In these cases, maximum internal equity of 27 is retained and committed to cover the market risk of the market-making activity in order to reduce the probability of facing 
a PCA penalty.

Absent PCA, the bank's globally optimal strategy is to invest 75 in market-making activities, 125 in loans 1 and 2, and 20 in risk free bonds. This strategy generates a share value of 60.97 and an insurance value of 0.34 gross of the bank's initial premium. Under the penalty rates examined, the application of PCA will not alter the bank's optimal investment strategy. Facing only a PCA capital requirement, the bank will optimally choose to pre-commit its total available equity capital (27) and continue its unregulated optimal operating strategy. The PCA will lower the bank's share value only slightly, and reduce the value of its insurance guarantee so that, on balance, the bank is over-charged for deposit insurance.

In summary, for most of the individual investment alternatives illustrated in Table 4, a PCA discourages a bank from taking market risk exposure simply to exploit the deposit insurance guarantee. If the bank chooses to take on market risk exposure through a profitable market-making operation, PCA encourages the bank to retain inside equity capital and pre-commit to reduce the probability of a penalty. However, similar to the examples reported in Table 2, if a bank's unregulated optimal loan portfolio requires only a modest investment relative to the bank's insured deposit base, a PCA may be ineffective in discouraging a bank from taking market risk exposure if the bank has the opportunity to conduct proprietary trading activities using market-traded securities with substantial risk. Regardless of its effectiveness to completely remove bank incentives to invest in 0 NPV risky market-traded securities, the PCA clearly limits a bank's ability to exploit the deposit insurance guarantee.

\section{Designing the PCA Penalty Function}

The prior analysis has established that a fixed penalty rate PCA can be effective in limiting the aggregate BIF subsidy to the banking system. Within this fixed penalty structure, the PCA will be most effective if penalty rates are bank specific. As demonstrated in the previous illustrations, a modest uniform PCA penalty rate 
will induce some banks to limit risk in their trading accounts but will not deter other banks. While a uniform high penalty rate will maximize the effectiveness of the PCA, it will also tend to over-charge banks for whom a low rate is effective and who have positive NPV market-making activities. Moreover, excessive PCA penalty rates could discourage some banks from undertaking positive NPV market-making activities.

The adoption of a PCA that uses custom-tailored bank specific penalty rates, while theoretically appealing, is unlikely to be either desirable or feasible. Such a scheme would require that the regulator know individual banks' investment opportunity sets as well as other bank-specific information, effectively requiring the regulator to achieve a familiarity with the operations of individual banks on a level equivalent to that of a bank insider. Not only is such activity inconsistent with the implicit PCA goal of reducing regulatory intrusiveness, such a procedure would result in significant variation in penalty rates among banks. Given the inherent subjective nature of the rate setting process, such variation could undermine the political feasibility of a PCA approach.

Although bank-specific penalty functions may not be practical, some flexibility in the penalty rate structure may still be possible. Given a PCA penalty rate, when banks have less than perfect access to capital markets it can be shown that the strength of the risk-reducing incentives created by a PCA vary directly with the amount of equity in the bank's capital structure. This relationship can be used to enhance the effectiveness of the PCA. For example, a more effective PCA penalty structure might be a design in which penalty rates are conditioned on an objective measure of the bank's capital (e.g., its overall leverage ratio) at the time the bank makes its maximum loss pre-commitment. Banks with higher levels of equity capital (lower leverage ratios) would face lower PCA penalty rates. Such a schedule uses the information implicit in a bank's choice of capital structure. Banks that hold significant equity capital are revealing that they intend to follow a relatively safe investment strategy. Conversely, banks that hold little or no equity capital are more 
likely to have strong incentives to take significant risks. Banks not satisfying the PCA maximum leverage constraint could be required to use some alternative system of capital regulation and would likely warrant more intensive supervision.

\section{Conclusions}

Within the context of a model of a bank facing a fixed rate deposit insurance system, it has been demonstrated that the PCA, operationalized using a fixed monetary penalty rate, imposes a contingent liability on the bank whose value increases with the market risk in a bank's trading account and decreases with the size of a bank's pre-commitment. Unlike the current Basle schemes for setting market risk capital requirements, the PCA provides an explicit incentive mechanism for committing adequate capital to cover a level of market risk that is known only to the bank. Moreover, the PCA involves minimum intrusion into the bank's affairs.

The theoretical analyses presented in this study suggests that, given the real world frictions that characterize banks' access to capital markets, the pre-commitment approach for setting market risk capital requirements for bank trading accounts can create incentives that discourage banks from using their trading account activities to exploit their deposit insurance guarantee. The results suggest that a PCA with only a modest penalty rate can substantially decrease the risk to the BIF arising from market risk-taking activity. If banks are engaged in profitable market-making operations, the PCA will encourage them to pre-commit capital to reduce the probability of incurring a PCA penalty. Alternatively, if a bank's optimal loan portfolio leaves it with substantial insured deposits to fund market risk-taking activities, PCA penalties may not discourage the bank from taking large market risk exposures. While in certain cases a PCA may be ineffective in removing incentives for a bank to invest in zero NPV risky securities, it clearly limits a bank's ability to use such means to exploit the deposit insurance guarantee.

While this characterization of the efficacy of the PCA may be weaker than one 
might hope for, our inability to draw stronger conclusions owes to the generality of the model's assumptions. If the model were specialized, for example, by assuming that loan portfolio NPV's and risk were functionally related, one could draw stronger conclusions regarding both the effectiveness of the PCA and the most appropriate design of a penalty function. In our view, however, there is no basis for making such an assumption.

Although the PCA has important advantages over the alternate BSC-approved market risk capital schemes, it shares the shortcomings inherent in the "piecemeal" approach to bank capital regulation that has been adopted by regulatory authorities. All of these market risk guidelines set capital to cover risks in banks' trading activities without regard to the risks created by other activities in the bank. The present analysis indicates that the PCA, although a piecemeal approach to trading account risk, can reduce the distorting effects of flat rate deposit insurance when viewed from a whole-bank perspective. However, all piecemeal approaches share at least two critical shortcomings. They create category capital charges that are additive across bank activities while the risks themselves are not additive. Piecemeal capital schemes also are susceptible to circumvention through regulatory arbitrage in which equivalent risks are, in essence, renamed and shifted among regulatory risk categories to minimize the bank's cost of capital regulation. In these regards, the PCA is no better that the existing regulatory capital requirements for market risk. 


\section{Appendix}

\section{Derivation of expression (3) using equivalent martingale pricing}

Let $\mathrm{L}$ represent the set of loans in a bank's optimal loan portfolio and $\mathrm{R}$ represent the set of risky market-traded securities in a bank's optimal trading account portfolio. Define $j_{1}$ to be the end-of-period cash flow generated by the bank's total risky investment portfolio,

$$
\begin{aligned}
j_{1} & =j_{L 1}+j_{M 1} \\
j_{L 1} & =\sum_{(\forall i \in L)} j_{L_{i} 1} \quad \text { and, } \quad j_{M 1}=\sum_{(\forall i \in R)} j_{M_{i} 1}
\end{aligned}
$$

Let $I$ represent the total initial investment in loans, and $M$ represent the total investment in market traded securities,

$$
I=\sum_{(\forall i \in L)} I_{i}, \quad \text { and } \quad M=\sum_{(\forall i \in R)} M_{i}
$$

The total end-of-period cash flow value that accrues to the bank's shareholders including the bank's franchise value net of any distress costs is,

$$
\begin{gathered}
j_{1}+T e^{r}+J-B \quad \text { for } \quad j_{1}>j_{d s} \\
j_{1}+T e^{r}+J-B-\left(\frac{d_{1}}{1-d_{1}}\right)\left(B-j_{1}-T e^{r}\right) \text { for } \quad j_{d}<j_{1}<j_{d s} \\
0 \text { for } \quad j_{1}<j_{d} \\
\text { where, } j_{d s} \equiv B-T e^{r} \\
j_{d} \equiv B-T e^{r}-\left(1-d_{1}\right) J .
\end{gathered}
$$

These end-of-period cash flows can be expressed more compactly as,

$$
j_{1}+T e^{r}+J-\frac{d_{1}}{1-d_{1}} \max \left[j_{d s}-j_{1}, 0\right]+\frac{d_{1}}{1-d_{1}} \max \left[j_{d}-j_{1}, 0\right]+\max \left[j_{d}-j_{1}, 0\right]
$$

The risk-adjusted present value of the end-of-period cash flows can be determined using an absence of arbitrage condition. Under an absence of arbitrage, the expected return on 
a risk-adjusted basis will equal the risk-free rate plus an adjustment involving the asset return's volatility due to Jensen's inequality,

$$
\log \left(j_{i 1}\right)-\log \left(j_{i 0}\right)=r-\frac{1}{2} \sigma_{i}^{2}+s_{i}^{\top} \lambda+s_{i}^{\top} z_{1}
$$

where $\lambda$ is the vector of market prices of risk. Substituting expression (1) in the text for $j_{i 1}$ above and solving for $j_{i 0}$ yields the valuation in expression (2). Valuation procedures can be simplified by taking expectations of payoffs under an equivalent martingale probability measure. For this purpose, asset $i$ 's return process is modified into an equivalent process $\mu_{i}^{w}+s_{i}^{\top} z_{1}^{w}$ where $\mu_{i}^{w} \equiv \mu_{i}-s_{i}^{\top} \lambda$ and $z_{1}^{w} \equiv z_{1}+\lambda$. The absence of arbitrage condition implies that the asset value discounted by the risk-free rate follows a martingale under the redefined process where $\mu_{i}^{w}$ replaces $\mu_{i}$ and $z_{1}^{w}$ is a standard normal variate replacing $z_{1}$ under the change of measure. Letting $E^{w}$ denote the expectations operator under the redefined process,

$$
j_{i 0}=e^{-r} E^{w}\left(j_{i 1}\right)=e^{-r} V_{i} e^{\mu_{i}^{w}+\frac{1}{2} \sigma_{i}^{2}}=V_{i} e^{\mu_{i}+\frac{1}{2} \sigma_{i}^{2}-\lambda^{\top} s_{i}-r}
$$

$\forall i$. Thus the risk-adjusted present value of the bank's market-traded securities portfolio is,

$$
e^{-r} E^{w}\left(j_{M 1}\right)=\sum_{(\forall i \in R)} e^{-r} M_{i} e^{\mu_{M_{i}}^{w}+\frac{1}{2} \sigma_{M_{i}}^{2}}=\sum_{(\forall i \in R)} M_{i} e^{r-r}=M
$$

In the text and numerical examples in the paper, the value of a bank's market portfolio of risky market-traded securities is treated as a single lognormal variable. This simplification is useful and inconsequential. The risk-adjusted present value of the bank's loan portfolio, $j_{L 0}$, is

$$
j_{L 0}=\sum_{(\forall i \in L)} j_{L_{i} 0}=e^{-r} \sum_{(\forall i \in L)} E^{w}\left(j_{L_{i} 1}\right)=e^{-r} \sum_{(\forall i \in L)} I_{L_{i}} e^{\mu_{L_{i}}+\frac{1}{2} \sigma_{L_{i}}^{2}-\lambda^{\top} s_{L_{i}}-r}
$$

$j_{L 0}+M$ is the risk-adjusted present value of the bank's total end-of-period cash flows from risky assets.

$J$ represents the expected value of the bank's franchise, here taken to be an asset of fixed value that can be realized at the end of period 1 . Thus the franchise value at the start 
of period 1 is $e^{-r} J$. Similarly, $T e^{r}$ is a certain payment at the end of period 1 from a bank's risk-free bond investments, so its present value is $T$.

The remaining components of the the end-of-period value expression are equivalent to the cash flow payoffs that would be produced by positions in long and short European-style put options (with strikes prices of $j_{d s}$ and $j_{d}$ ) written on the underlying risky asset portfolio with payoff $j_{1}$. Their initial period values are

$$
\begin{aligned}
P_{D} & =e^{-r} E^{w}\left[\max \left[j_{d s}-j_{1}, 0\right]\right] \\
P_{I} & =e^{-r} E^{w}\left[\max \left[j_{d}-j_{1}, 0\right]\right]
\end{aligned}
$$

If $j_{1}$ was lognormal, these options would have familiar Black-Scholes closed form valuations. As $j_{1}$ is distributed according to the sum of lognormal variables, Black-Scholes will not apply.

The bank's equity shares have a gross value equal to: the net value of the aforementioned cash flows, $\left(j_{L 0}+M+T+\frac{d_{1}}{1-d_{1}} P_{D}+\frac{d_{1}}{1-d_{1}} P_{I}+P_{I}\right)$, plus the up-front deposit liquidity service payments, $e^{-r} B \pi$, less the deposit insurance premium payments, $\phi B e^{-r}$, less initial outside equity financing costs. Outside equity financing generates costs of $d_{0}$ per-dollar of outside equity raised. The outside equity financing requirement is are given by,

$$
E=\frac{1}{1-d_{0}} \max \left\{I+M+T+\Phi(B)-(1+\pi) B e^{-r}-W, 0\right\}
$$

Shareholder's net equity value (expression (3)) is derived by subtracting the initial investments in bonds, loans and market-traded securities, $I+T+M$.

\section{Derivation of Expression (5)}

Under the PCA, the end-of-period cash flows that accrue to the bank's shareholders are given by,

$$
\begin{aligned}
j_{L 1} & +j_{M 1}+T e^{r}+J^{*}-B-\Upsilon \max \left[C-j_{M 1}, 0\right] \\
& -\frac{d_{1}}{1-d_{1}} \max \left[B-T e^{r}-j_{L 1}-j_{M 1}+\Upsilon \max \left[C-j_{M 1}, 0\right]\right] \\
& +\max \left\{\left[B-T e^{r}+\Upsilon \max \left[C-j_{M 1}, 0\right]-J-j_{L 1}-j_{M 1}\right.\right.
\end{aligned}
$$




$$
\left.+\frac{d_{1}}{1-d_{1}} \max \left(\left\{B-T e^{r}-j_{L 1}-j_{M 1}+\Upsilon \max \left[C-j_{M 1}, 0\right]\right\}, 0\right), 0\right\}
$$

Upon rearranging these cash flows, finding their present value using equivalent martingale pricing measures, including the initial insurance premium, service fee profits, and equity issuance costs, one can reconstruct expression (5) in the text where,

$$
\begin{aligned}
P_{I}^{\prime} & =e^{-r} E^{w}\left[\max \left\{\left(B+\Upsilon \max \left\{\left(C-j_{M 1}\right), 0\right\}-T e^{r}-\left(1-d_{1}\right) J-j_{1}\right), 0\right\}\right] \\
P_{D}^{\prime} & =e^{-r} E^{w}\left[\max \left\{\left(B-T e^{r}+\Upsilon \max \left\{\left(C-j_{M 1}\right), 0\right\}-j_{1}\right), 0\right\}\right] \\
P_{C} & =e^{-r} E^{w}\left[\max \left\{C-j_{M 1}, 0\right\}\right] .
\end{aligned}
$$

\section{The valuation of bank cash flows under the PCA}

The pre-commitment penalty function substantially complicates the valuation of the distress costs and insurance option values. To our knowledge, there exits no closed-form valuation expression for these options. The analytical intractability arises because, under the PCA, both the default option, $P_{I}^{\prime}$, and distress costs, $P_{D}^{\prime}$, now depend on several functions of different stochastic processes. Although, to our knowledge, the bank's end-of-period cash flows do not conform with cash flows produced by option pricing models with closed form solutions, the cash flow payoffs are closely related to some specialized options.

If one defines,

$$
\begin{aligned}
j_{a}= & j_{L 1}+j_{M 1}+T e^{r}+J \\
j_{b}= & j_{L 1}+j_{M 1}+T e^{r}+J-\Upsilon\left(C-j_{M 1}\right), \\
j_{c}= & j_{L 1}+j_{M 1}+T e^{r}+J-\frac{d_{1}}{1-d_{1}}\left(B-T e^{r}-\left(j_{L 1}+j_{M 1}\right)\right), \\
j_{d}= & j_{L 1}+j_{M 1}+T e^{r}+J- \\
& \frac{d_{1}}{1-d_{1}}\left(B+\Upsilon\left(C-j_{M 1}\right)-T e^{r}-\left(j_{L 1}+j_{M 1}\right)\right)-\Upsilon\left(C-j_{M}\right) .
\end{aligned}
$$

shareholder's end-of-period cash flows can be written as,

$$
\max \left\{\min \left\{j_{a}, j_{b}, j_{c}, j_{d}\right\}-B, 0\right\}
$$


Written in this form, the end-of-period cash flows mimic those of a European call on the minimum of $\left(j_{a}, j_{b}, j_{c}, j_{d}\right)$ with an exercise price of $B$. Under the assumption that all the underlying processes $\left(j_{a}, j_{b}, j_{c}, j_{d}\right)$ follow geometric Brownian motion and are markettraded assets, Johnson (1987) provides a closed-form solution for such a call option. ${ }^{29}$ The closed-form solution however is not applicable in the present context. If the underlying values $j_{L 1}$ and $j_{M 1}$ are lognormally distributed, the values in the call options, $\left(j_{a}, j_{b}, j_{c}, j_{d}\right)$, will not follow geometric Brownian motion. Moreover, the underlying multivariate normal distribution explicit in the closed form value of the call option is not of full rank as $j_{a}$ is perfectly correlated with $j_{c}$, and $j_{b}$ is perfectly correlated with $j_{d}$.

This singularity can be removed by re-formulating the problem. Define $j_{S 1}=j_{L 1}+$ $(1+\Upsilon) j_{M 1}$. Using this definition and the definition, $j_{1}=j_{L 1}+j_{M 1}$, the call option's end-of-period cash flows can be written as,

$$
\max \{\min \{x, y\}, 0\}
$$

where,

$$
\begin{aligned}
& x=j_{1}+T e^{r}+J-B-\frac{d_{1}}{1-d_{1}} \max \left\{B-T e^{r}-j_{1}, 0\right\} \\
& y=j_{S 1}+T e^{r}+J-B-\Upsilon C-\frac{d_{1}}{1-d_{1}} \max \left\{B+\Upsilon C-T e^{r}-j_{S 1}, 0\right\} .
\end{aligned}
$$

Written in this form, end-of-period cash flows are equivalent to those produced by a European call option on the minimum of two synthetic processes, $x$ and $y$, each with a strike price of 0 . The synthetic processes $x$ and $y$ can themselves be interpreted as the end-of-period payoffs from an investment of $(J-B) e^{-r}+T$ in the risk free asset plus a long position in the underlying process $\left(j_{S 1}\right.$ or $\left.j_{1}\right)$, and a short position of $\frac{d_{1}}{1-d_{1}}$ put options on the underlying process. Thus, the present value of the end-of-period cash flows are equivalent to a compound European call option on the minimum of two process - that is, each of the underlying processes has an embedded option that in part determines its value. Again, we

\footnotetext{
${ }^{29}$ Johnson(1987) generalizes the results of Stulz(1982) and derives a closed-form solution for the value of such a European call option on the minimum of several variables.
} 
are unaware of any closed-form expressions for this call value. Valuations nonetheless can be obtained using numerical methods.

\section{Proof of Propositions and Corollaries}

The end-of period values for any loan $k\left(j_{L_{k} 1}\right)$ or risky security portfolio $\left(j_{M 1}\right)$ have been assumed to be distributed lognormally. To formally prove the propositions and corollaries in Section 5 of the text, we further specialize the assumptions of the model so that the bank chooses among a set of loan portfolios, each of which has a lognormal distribution. With this additional assumption, the end-of-period value of the bank's risky assets $\left(j_{1}=j_{L_{k} 1}+j_{M 1}\right)$ is the sum of two lognormal variables. The additional specialization greatly simplifies the proofs by limiting the dimension of the distribution function of the sums of lognormal variables.

Although $j_{L_{k} 1}$ and $j_{M 1}$ have actual lognormal distributions by assumption, the lognormal distributions of interest are the distributions implied by the equivalent martingale measure; that is, the distribution of the end-of-period realizations generated under expression (1) when $\mu_{i}$ is replaced by its equivalent martingale form $\mu_{i}^{w}$ and $z(t)$ is replaced by $z^{w}(t)$, the equivalent martingale standard normal process.

In the lemmas that follow, we will consider end-of-period values as individual asset volatilities, $\sigma_{i}^{2}$, get infinitely large while the assets' risk-neutral drifts, $\mu_{i}^{w}$, are assumed to remain unchanged. One way for this to occur is for the increased volatility to come from increases in the size of the non-systematic components of $s_{i}$ whose market price of risk are zero.

Define $F_{n}\left(n_{1}\right)$ to be the cumulative distribution (CDF) function of the random variable $n$ evaluated at $n_{1}\left(n=L_{k}, M, j=L+M\right)$, and $f_{n}\left(n_{1}\right)$ as the corresponding density function (PDF), both defined under the equivalent martingale measure.

For proving the propositions and corollaries in section 5, some lemmas first need to be established.

Lemma 1 For any $j_{M 1} \ll \infty$, and any nonnegative finite investment $M$, (i) $\lim _{\sigma_{M} \rightarrow \infty}$ $F_{M}\left(j_{M 1}\right) \rightarrow 1$ uniformly; and (ii) $\lim _{\sigma_{M} \rightarrow \infty} f_{M}\left(j_{M 1}\right) j_{M 1} \rightarrow 0$ uniformly. 
proof: Using a change of variables, $F_{M}\left(j_{M 1}\right)=N_{z}\left(z_{1}\right)$ where $N_{z}\left(z_{1}\right)$ is a standard normal CDF and $z_{1}=\ln \left(\frac{j_{M 1}}{M}\right) \frac{1}{\sigma_{M}}-\frac{\mu_{M}^{w}}{\sigma_{M}}+.5 \sigma_{M} \cdot \lim _{\sigma_{M} \rightarrow \infty} N_{z}\left(z_{1}\right)=N_{z}\left(\lim _{\sigma_{M} \rightarrow \infty} z_{1}\right)=$ $N_{z}(+\infty)=1$. Further, $F_{M}\left(j_{M 1}\right)$ and $N_{z}\left(z_{1}\right)$ are continuous in $\sigma_{M}$ for all $j_{M 1} \in(0, \infty)$ so that $F_{M}\left(j_{M 1}\right)$ converges uniformly. With uniform convergence, $\lim _{\sigma_{M} \rightarrow \infty} f_{M}\left(j_{M 1}\right)=$ $\frac{d\left(\lim _{\sigma_{M} \rightarrow \infty} F_{M}\left(j_{M 1}\right)\right)}{d j_{M 1}}=0$ from which (ii) in Lemma 1 follows immediately. ${ }^{30}$

Conjecture 1 For any $j_{M 1} \ll \infty$ and any nonnegative investment $M$, (i) $\lim _{\sigma_{M} \rightarrow \infty} F_{j}\left(j_{1}\right)$ $\rightarrow F_{L_{k}}\left(j_{1}\right)$ uniformly; and (ii) $\lim _{\sigma_{M} \rightarrow \infty} f_{j}\left(j_{1}\right) j_{1} \rightarrow f_{L_{k}}\left(j_{1}\right) j_{1}$ uniformly.

Because the distribution of the sum of lognormal variables does not have any simple analytic form, we are not able to prove this conjecture analytically. However, the limits in the conjecture can be verified numerically. Further, the intuition for the conjecture follows from Lemma 1. As the volatility of the risky market security increases without bound, its CDF uniformly approaches a distribution where virtually all the mass is concentrated at zero so that the probability that $j_{M 1} \gg 0$ approaches 0 . Therefore, the conjecture is that, for the sum of the lognormal random variables, $j_{1}=j_{L_{k} 1}+j_{M 1}$, the CDF for $j_{1}$ approaches the CDF for $j_{L_{k} 1}$ as $\sigma_{M} \rightarrow \infty$.

The following lemmas establish properties of the deposit insurance value when the bank has access to 0 NPV securities with unbounded risk.

Lemma 2 In the absence of the PCA, the deposit insurance value, for a given loan portfolio $k$, is $P_{I}\left(L_{k}\right)=e^{-r} E^{w}\left[\max \left\{j_{d}-j_{1}, 0\right\}\right]$ where $j_{d}=\bar{B}-T-J e^{-r}$ and $j_{1}=j_{L k 1}+$ $j_{M 1}$. For a risky security investment with unbounded risk, $P_{I}\left(L_{k}\right)$ has the properties (i) $\lim _{\sigma_{M} \rightarrow \infty} P_{I}\left(L_{k}\right)=e^{-r} E^{w}\left[\max \left\{j_{d}-j_{L_{k} 1}, 0\right\}\right] ;$ (ii) $e^{-r} E^{w}\left[\max \left\{j_{d}-j_{L_{k} 1}, 0\right\}\right]$ is a maximum for all permitted risky securities strategies (i.e., the insurance value given loan portfolio $L_{k}$ is maximized by choosing a securities investment with unbounded risk).

proof: Part (i) is proved using Conjecture 1 (i) and (ii).

$$
\lim _{\sigma_{M} \rightarrow \infty} P_{I}\left(L_{k}\right)=\lim _{\sigma_{M} \rightarrow \infty} e^{-r}\left\{j_{d} F_{j}\left(j_{1}\right)-\int_{0}^{j_{d}} j_{1} f_{j}\left(j_{1}\right) d j_{1}\right\}
$$

\footnotetext{
${ }^{30}$ For theorems on limit functions and uniform convergence, see Rektorys (1969), Chp. 15.
} 


$$
\begin{aligned}
& =e^{-r}\left(j_{d} \lim _{\sigma_{M} \rightarrow \infty} F_{j}\left(j_{1}\right)-\int_{0}^{j_{d}} \lim _{\sigma_{M} \rightarrow \infty}\left\{j_{1} f_{j}\left(j_{1}\right)\right\} d j_{1}\right) \\
& \left.=e^{-r}\left(j_{d} F_{L_{k}}\left(j_{L_{k} 1}\right)-\int_{0}^{j_{d}} j_{L_{k} 1} f_{L_{k}}\left(j_{L_{k} 1}\right)\right\} d j_{L_{k} 1}\right) \\
& =e^{-r} E^{w}\left[\max \left\{j_{d}-j_{L_{k} 1}, 0\right\}\right] .
\end{aligned}
$$

To prove part (ii) note that the insurance payoff is $\max \left\{j_{d}-\left(j_{L_{k} 1}+j_{M 1}\right), 0\right\}$. Since $j_{M 1} \geq 0$, the payoff for any realization $j_{L_{k} 1}$ is a maximum if $j_{M 1}=0$. Multiplying each possible insurance payoff by its (equivalent martingale) probability given $j_{M 1}=0$ also must give the maximum probability-weighted payoff for any $j_{L_{k} 1}$ realization. Therefore, given loan portfolio $k$, the discounted sum of the probability-weighted insurance payoffs must be a maximum as well. The discounted sum of the probability-weighted payoffs is $e^{-r} E^{w}\left[\max \left\{j_{d}-j_{L_{k}}, 0\right\}\right]$ which (i) established is the payoff obtained with a securities investment having unbounded risk. This proves part (ii).

Since the insurance payoff is $\max \left\{j_{d}-j_{1}, 0\right\}$ and $j_{1} \geq 0$, the absolute maximum payoff is $\max \left\{j_{d}, 0\right\}$. This sets an upper bound on how much the insurance can be worth to the bank. The following two lemmas establish conditions for achieving this bound with maximum loan and security risk.

Lemma $3 A$ bank that invests all its funds in the risky security with unbounded risk achieves the maximum insurance value; i.e., $\lim _{\sigma_{M} \rightarrow \infty} P_{I}=e^{-r} \max \left\{j_{d}, 0\right\}$.

Lemma 4 For a bank that invests its funds in both loans and risky securities, $\lim _{\sigma_{L_{k}} \rightarrow \infty}$ $\lim _{\sigma_{M} \rightarrow \infty} P_{I}=e^{-r} \max \left\{j_{d}, 0\right\}$.

proof: For Lemma 3, the bank's asset portfolio is the risky security portfolio with end-ofperiod value $j_{M 1}$ and $\lim _{\sigma_{M} \rightarrow \infty} P_{I}=\lim _{\sigma_{M} \rightarrow \infty} e^{-r} E^{w}\left[\max \left\{j_{d}-j_{M 1}, 0\right\}\right]$. For $j_{d} \leq 0$, this limit is 0 . For $j_{d} \gg 0$, the limit is $e^{-r}\left(\left\{j_{d} \lim _{\sigma_{M} \rightarrow \infty} F_{M}\left(j_{M 1}\right)-\int_{0}^{j_{d}} \lim _{\sigma_{M} \rightarrow \infty}\left\{j_{M} f_{M}\left(j_{M 1}\right)\right\} d j_{1}\right)=\right.$ $e^{-r} j_{d}$

To prove Lemma 4, first apply $\lim _{\sigma_{M} \rightarrow \infty}$ to $P_{I}$ when the bank invests in both loans and risky securities. By lemma 2, this yields an insurance value written on the loan portfolio 
with lognormal end-of-period value $j_{L_{k} 1}$. Next apply Lemma 1 (using " $L_{k}$ " instead of " $M$ ") to get Lemma 4. That is, $\lim _{\sigma_{L_{k}} \rightarrow \infty}\left\{\lim _{\sigma_{M} \rightarrow \infty} P_{I}\right\}=\lim _{\sigma_{L_{k}} \rightarrow \infty} P_{I}\left(L_{k}\right)=e^{-r} \max \left\{j_{d}, 0\right\}$.

The final lemma applies to the value of deposit insurance under the PCA.

Lemma 5 Under the PCA, the value of the bank's deposit insurance net of the value of the PCA put option is $P_{I}^{\prime}-\Upsilon P_{C}$ as formally defined in Appendix 2. If the bank's risky asset portfolio is limited to risky securities, then $\lim _{\sigma_{M} \rightarrow \infty}\left\{P_{I}^{\prime}-\Upsilon P_{C}\right\}=e^{-r} \max \left\{j_{d},-\Upsilon C\right\}$.

proof: Since $P_{C}$ is a put option written only on the risky security with exercise price of $C$, Lemma 3 implies $\lim _{\sigma_{M} \rightarrow \infty} \Upsilon P_{C}=e^{-r} \Upsilon C$. Now express $P_{I}^{\prime}$ in the form $P_{I}^{\prime}=E^{w}\left[P_{I}^{\prime} \mid j_{M 1} \leq\right.$ $C] F_{M}(C)+E^{w}\left[P_{I}^{\prime} \mid j_{M} 1 \gg C\right]\left(1-F_{M}(C)\right)$. Apply $\lim _{\sigma_{M} \rightarrow \infty}$ to this expression and pass through the limits using the properties that the limit of a sum is the sum of the limits and the limit of a product is the product of the limits. Lemma 1 implies $\lim _{\sigma_{M} \rightarrow \infty} F_{M}(C)=1$. Use this to get $\lim _{\sigma_{M} \rightarrow \infty}\left\{E^{w}\left[P_{I}^{\prime} \mid j_{M 1} \leq C\right] F_{M}(C)+E^{w}\left[P_{I}^{\prime} \mid j_{M 1} \gg C\right]\left(1-F_{M}(C)\right)\right\}=$ $\lim _{\sigma_{M} \rightarrow \infty} E^{w}\left[P_{I}^{\prime} \mid j_{M 1} \leq C\right]$. From Lemma 3, this limit is $e^{-r} \max \left\{j_{d}+\Upsilon C, 0\right\}$. Summing yields $\lim _{\sigma_{M} \rightarrow \infty} P_{I}^{\prime}-\lim _{\sigma_{M} \rightarrow \infty} \Upsilon P_{C}=e^{-r} \max \left\{j_{d},-\Upsilon C\right\}$.

\section{Proof of Proposition 1}

Proposition 1 can now be proven where the end-of-period loan portfolio $\left(j_{L 1}\right)$ and risky securities portfolio $\left(j_{M 1}\right)$ each take the lognormal forms defined above. When $\Upsilon=d_{0}=$ $d_{1}=0$, the bank's SNB value given loan portfolio $L_{k}$ is

$$
\operatorname{SNB}\left(L_{k}\right)=P_{I}\left(L_{k}\right)+(\pi-\phi) \bar{B} e^{-r}
$$

where $P_{I}\left(L_{k}\right)=e^{-r} E^{w}\left[\max \left\{j_{d}-\left(j_{L_{k} 1}+j_{M 1}\right), 0\right\}\right]$.

First consider the case where the bank costlessly adjusts its investment in risk-free securities $T$ such that $j_{d}\left(\equiv \bar{B}-T e^{r}-J e^{r}\right) \leq 0$, assuming the bank issues maximum deposits (i.e., assuming $\pi \geq \phi$ ). Since the end-of-period value on the bank's loans and securities cannot be negative, when $j_{d} \leq 0, P_{I}\left(L_{k}\right)=0 \forall k$ and the bank is free of default risk. In this case, the bank's net share value, $S$, is, $S=j_{L_{k} 1}-I_{k}+(\pi-\phi) \bar{B} e^{-r}+J e^{-r}$. Under this default-free strategy, $S$ is maximized by maximizing loan portfolio NPV, yielding

$$
S_{F}^{*}=\max \left\{j_{L_{k} 1}-I_{k}\right\}+(\pi-\phi) \bar{B} e^{-r}+J e^{-r} .
$$


If the bank sets $j_{d} \gg 0$, it faces default risk and $P_{I} \gg 0$. There are two types of investment strategies that need to be considered. One is where the bank limits its investments to 0 NPV risky securities. From Lemma 3, the bank will maximize its deposit insurance value, and hence SNB, by securities investments with unbounded risk which yields $\mathrm{SNB}=\bar{B} e^{-r}(1+\pi-\phi)-T-J e^{-r}$ which is maximized by setting $T=0$. Since the bank has no loan portfolio, it's net shareholder value is given by,

$$
S_{R}^{*}=\bar{B} e^{-r}(1+\pi-\phi),
$$

$S_{R}^{*}$ is a "go-for-broke" strategy as the bank is taking maximum default and securities risk to maximize its deposit insurance value.

The other strategy to consider is when the bank's investment also includes a risky loan portfolio $k$. The deposit insurance payoff is $\max \left\{j_{d}-\left(j_{L_{k} 1}+j_{M 1}\right), 0\right\}$. Lemma 2 established that the insurance value, given loan portfolio $k$, is a maximum when risky securities investments have maximum (unbounded) risk, i.e., $\lim _{\sigma_{M} \rightarrow \infty} P_{I}\left(L_{k}\right)=e^{-r} E^{w}\left[\max \left\{j_{d}-\right.\right.$ $\left.\left.j_{L_{k} 1}, 0\right\}\right] \equiv P_{I}^{*}\left(L_{k}\right)$. Lemma 4 also implies $P_{I}^{*}\left(L_{k}\right) \leq \max \left\{j_{d}, 0\right\}$. This places an upper bound on $P_{I}^{*}\left(L_{k}\right)$. Further, $e^{-r} E^{w}\left[\max \left\{j_{d}-j_{L_{k} 1}, 0\right\}\right]=e^{-r}\left(\int_{0}^{j_{d}}\left(j_{d}-j_{L_{k} 1}\right) f_{L_{k}}\left(j_{L_{k} 1}\right) d j_{L_{k} 1}\right) \geq$ $e^{-r}\left(\int_{0}^{\infty}\left(j_{d}-j_{L_{k} 1}\right) f_{L_{k}}\left(j_{L_{k} 1}\right) d j_{L_{k} 1}\right)=e^{-r} j_{d}-j_{L_{k} 0}$ (i.e., an option value cannot be less than its "intrinsic value"). This places a lower bound on $P_{I}^{*}\left(L_{k}\right)$. Thus, the insurance value, given loan portfolio $\mathrm{k}$ and an optimal risky securities strategy, is bounded by

$$
\max \left\{j_{d}-j_{L_{k} 0}, 0\right\} \leq P_{I}^{*}\left(L_{k}\right) \leq \max \left\{j_{d}, 0\right\}
$$

Since $j_{d}=\bar{B}-T-J$, the maximization of the insurance value requires the bank to set $T=0$. These bounds on the maximum insurance value, given loan portfolio $k$, imply bounds on net shareholder value. Using $S\left(L_{k}\right)=j_{L_{k} 0}-I_{k}+\operatorname{SNB}\left(L_{k}\right)+J e^{-r}$ and $T=0$, 
the net shareholder value, $S^{*}\left(L_{k}\right)$, will satisfy the bounds ${ }^{31}$

$$
(1+\pi-\phi) \bar{B} e^{-r}-I_{k} \leq S^{*}\left(L_{k}\right) \leq j_{L_{k} 0}-I_{k}+(1+\pi-\phi) \bar{B} e^{-r}
$$

Under perfect access to capital markets, a bank with $\mathrm{N}$ loan portfolio alternatives will choose an investment strategy with a maximum net share value, $S^{*}$, that satisfies

$$
S^{*}=\max \left\{S_{F}^{*}, S_{R}^{*}, S^{*}\left(L_{1}\right), S^{*}\left(L_{2}\right), \ldots, S^{*}\left(L_{N}\right)\right\}
$$

Thus the bank's optimizing choice will depend on its opportunities for loan NPV and loan risk. In particular, $S_{F}^{*}$ depends on the maximum loan portfolio NPV in the bank's investment opportunity set. Further, the value of $S^{*}\left(L_{k}\right)$ depends on both NPV and risk for portfolio $L_{k}$. As developed above, the upper bound on $S^{*}\left(L_{k}\right)$ exceeds the maximum risk, "go-for-broke" strategy $\left(S_{R}^{*}\right)$ if $j_{L_{k} 0}-I_{k} \gg 0$. Whether there exists a loan portfolio $L_{k}$ such that $S^{*}\left(L_{k}\right) \gg S_{R}^{*}$ depends on the risk and NPV characteristics of the bank's loan investment opportunity set Also, a loan portfolio $k$ may have a smaller NPV than the portfolio with all positive NPV loans but the risk obtainable from the loan portfolio may be high enough such that $S^{*}\left(L_{k}\right)$ exceeds the safe-bank shareholder value, $S_{F}^{*}$.

Proof of Corollary 1

If all loans in the bank's investment opportunity set have 0 or negative NPVs, i.e., $j_{L_{k} 0}-I_{k} \leq 0$, the upper bound on $S^{*}\left(L_{k}\right)$ established above implies $S_{R}^{*} \geq S^{*}\left(L_{k}\right), \forall k$. That is, a bank will never choose a risky strategy with nonpositive NPV loan opportunities when 0 NPV infinite risk investments are available. Thus, for a bank with no positive NPV loan opportunities but infinite risk 0 NPV security opportunities, its optimizing choice set reduces to a securities-only "go-for-broke" strategy and a safe-bank strategy, i.e., $S^{*}=$ $\max \left\{S_{F}^{*}, S_{R}^{*}\right\}$. In this case, the bank's optimal choice set is independent of the characteristics of its loan investment opportunities.

\footnotetext{
${ }^{31}$ Note that a bank would never operate at the lower bond since it can achieve a higher net share value by making no loan investment, setting $I_{k}=0$, which is equivalent to selecting a "go-for-broke" yielding $S_{R}^{*}$.
} 
Proof of Proposition 2 From Corollary 1, when the bank has no positive loan NPV opportunities, its optimal investment choices will be limited to the securities-only "go-for-broke" strategy where the bank takes unbounded risk and a default-free strategy. Under a "go-forbroke" strategy $j_{d}>0>-\Upsilon C$, and so Lemma 5 can be used to establish that the bank's deposit insurance value net of the present value of the PCA contingent liability is equal to the value of deposit insurance under a "go-for-broke" strategy without the PCA. Thus, net shareholder value is equal to the "go-for-broke" value $S_{R}^{*}$ and independent of the PCA. Under a safe strategy, the bank has no incentive to take 0 NPV market risk. Thus it will not invest in risky securities, will pre-commit 0, and will obtain a net share value of $S_{F}^{*}$ independent of the PCA. Therefore, with no positive NPV loan opportunities, the PCA has no effect on the bank's optimal strategy. 


\section{References}

[1] Basel Committee on Banking Supervision (1993). The Supervisory Treatment of Market Risks, April, Bank for International Settlements, Basle Switzerland.

[2] Basel Committee on Banking Supervision (1995). The Supervisory Treatment of Market Risks, April, Bank for International Settlements, Basle Switzerland.

[3] Besanko, David and George Kanatas (1996). "The Regulation of Bank Capital: Do Capital Standards Promote Bank Safety?" Journal of Financial Intermediation, Vol. 5, No. 2, pp. 160-183.

[4] Campbell, Tim, Yuk-Shee Chan, and Anthony Marino, (1992). "An Incentive-Based Theory of Bank Regulation," Journal of Financial Intermediation, Vol. 2, pp. 255-276.

[5] Chan, Yuk-Shee, Stuart I Greenbaum, and Anjon Thakor, (1992). "Is Fairly-Priced Deposit Insurance Possible?" The Journal of Finance, Vol. 47, No. 1, pages 227-245.

[6] Dimson, Elroy, and Paul Marsh (1995). "Capital Requirements for Securities Firms," Journal of Finance, Vol. 50, No. 3, pp. 1219-1233.

[7] Duan, Jin-Chuan and Jean-Guy Simonato (1995). "Empirical Martingale Simulation for Asset Prices," McGill University, Montreal Canada.

[8] Federal Reserve Board, (1995a). Risk-Based Capital Standards: Market Risks, July.

[9] Federal Reserve Board, (1995b). Request for Comment on the Pre-Commitment Approach for Market Risks, docket No. R-0886, July.

[10] Gennotte, Gerard, and David Pyle (1991). "Capital Controls and Bank Risk," Journal of Banking and Finance, Vol. 15, No. 4/5, pp. 805-824.

[11] Giammarino, Ronald, Tracy Lewis, and David Sappington (1993). "An Incentive Approach to Banking Regulation," The Journal of Finance, Vol. 48, No. 4, pp. 1523-1541.

[12] John, K., T. John, and L. Senbet (1991). "Risk-shifting incentives of depository institutions: A new perspective on federal deposit insurance reform," Journal of Banking and Finance, Vol. 15, pp. 895-915.

[13] Johnson, Herb (1987). "Options On The Maximum Or The Minimum Of Several Assets," The Journal of Financial and Quantitative Analysis, Vol. 22, No. 3, pp. 277-284.

[14] Kupiec, Paul (1995). "Techniques for Verifying the Accuracy of Risk Measurement Models," Journal of Derivatives, Winter, pp. 73-84.

[15] Kupiec, Paul and James O’Brien (1995a). "The Use of Bank Measurement Models for Regulatory Capital Purposes," FEDS Working Paper No. 95-11, Federal Reserve Board, March. 
[16] Kupiec, Paul and James O'Brien (1995b). "A Pre-Commitment Approach to Capital Requirements for Market Risk," FEDS Working Paper No. 95-34, Federal Reserve Board, July.

[17] Kupiec, Paul and James O’Brien (1995c). "Internal Affairs," Risk, May, pp. 43-48.

[18] Kupiec, Paul and James O’Brien (1995d). "Model Alternative," Risk, June, pp. 37-41.

[19] Kupiec, Paul and James O'Brien (1996a). "Commitment is the Key," Risk, September, pp. $60-64$.

[20] Kupiec, Paul and James O’Brien (1996b). "Recent Developments in Bank Capital Regulation of Market Risks," in: Advances in Finance Investment and Banking: Derivatives, Regulation and Banking, Barry Schachter, editor. Amsterdam: North-Holland. Also available as FEDS Working Paper No. 95-11, Federal Reserve Board.

[21] Rektorys, Karel (1969). Survey of Applicable Mathematics, Cambridge: The M.I.T. Press.

[22] Stulz, Rene (1982). "Options On The Minimum Or The Maximum Of Two Risky Assets," The Journal of Financial Economics, Vol. 10, No. 2, pp. 161-185. 
Table 1

Alternative Loan Opportunity Sets

\begin{tabular}{|c|c|c|c|c|c|c|}
\hline $\begin{array}{c}\text { loan } \\
\text { number }\end{array}$ & $\begin{array}{c}\text { loan } \\
\text { amount }\end{array}$ & $\begin{array}{l}\text { expected } \\
\text { return }^{a}\end{array}$ & $\begin{array}{l}\text { systematic } \\
\left(\text { priced) } \text { risk }^{b}\right.\end{array}$ & $\begin{array}{c}\text { nonsystematic } \\
\text { risk }^{c}\end{array}$ & $\begin{array}{l}\text { total } \\
\text { risk }^{d}\end{array}$ & $\mathrm{NPV}^{e}$ \\
\hline \multicolumn{7}{|c|}{ Loan Opportunity Set A } \\
\hline 1 & 75 & .20 & .08 & .20 & .22 & 5.44 \\
\hline 2 & 50 & .10 & 0 & .45 & .45 & 2.56 \\
\hline 3 & 100 & .25 & .10 & .30 & .32 & 10.52 \\
\hline \multicolumn{7}{|c|}{ Loan Opportunity Set B } \\
\hline 1 & 75 & .30 & .10 & .50 & .51 & 12.14 \\
\hline 2 & 140 & .12 & .05 & .20 & .21 & 2.83 \\
\hline 3 & 50 & .20 & .10 & .60 & .61 & 2.56 \\
\hline \multicolumn{7}{|c|}{ Loan Opportunity Set C } \\
\hline 1 & 75 & .20 & .10 & .45 & .46 & 3.85 \\
\hline 2 & 100 & .03 & -.10 & .35 & .36 & 8.33 \\
\hline 3 & 50 & .20 & .12 & .45 & .47 & 1.52 \\
\hline \multicolumn{7}{|c|}{$\underline{\text { Risky Market-Traded Security }}$} \\
\hline & &.$\overline{35}$ & .30 & .30 & .42 & 0 \\
\hline
\end{tabular}

\footnotetext{
${ }^{a} 1$-period expected return to loan i, $\mu_{i}$.

${ }^{b} 1$-period systematic risk (standard deviation) for loan i, $s_{0 i}$

${ }^{c} 1$-period nonsystematic (idiosyncratic) risk for loan $\mathrm{i}, s_{1 i}$.

${ }^{d}$ Total risk for loan i (1-period return standard deviation), $\sigma_{i}=\left(s_{0 i}^{2}+s_{1 i}^{2}\right)^{\frac{1}{2}}$

${ }^{e} \mathrm{NPV}$ is calculated using expression(2) in the text where the market price of systematic risk is $1, \lambda=(1,0)$, and $r=.05$ is the risk-free rate.
} 


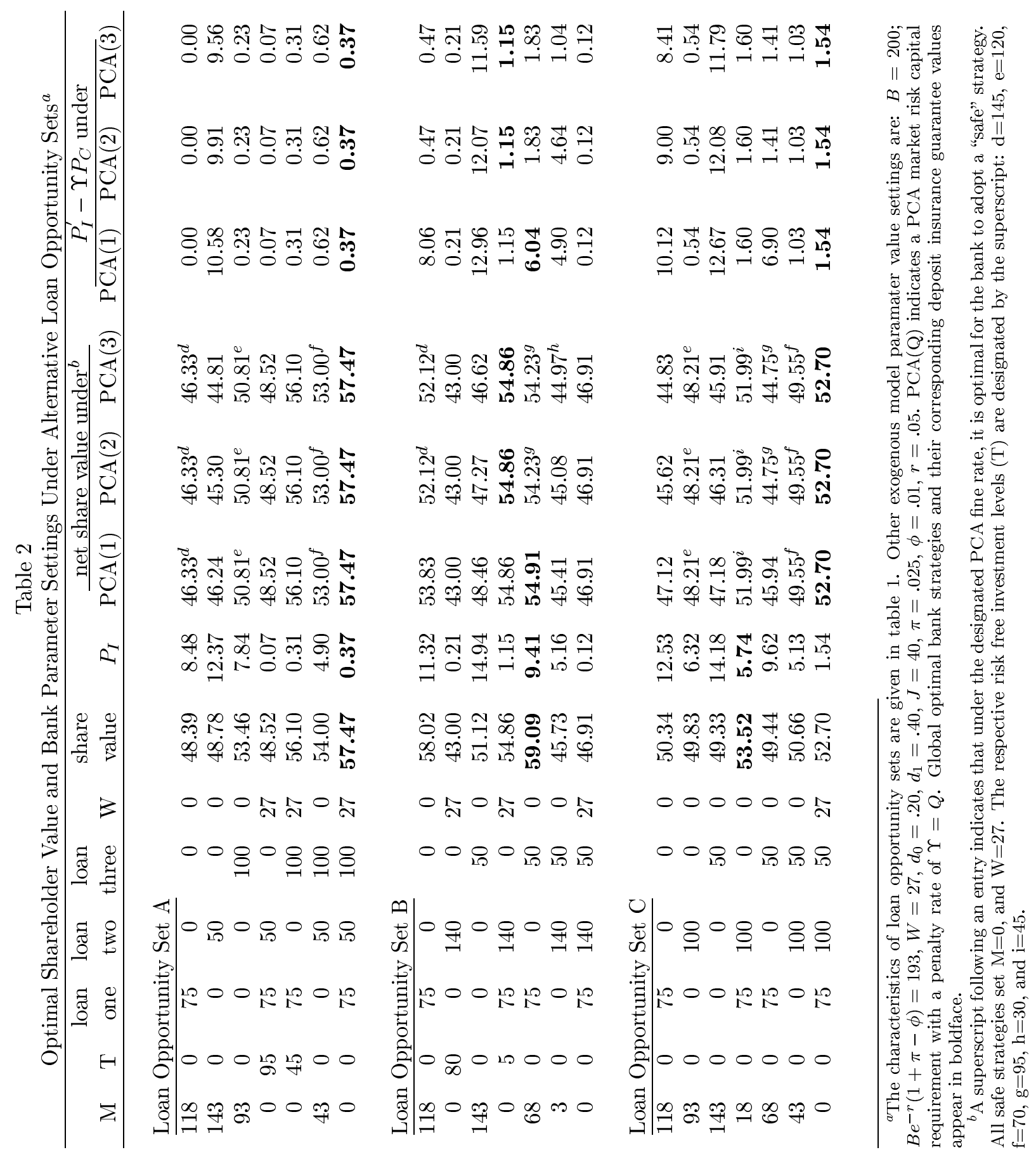




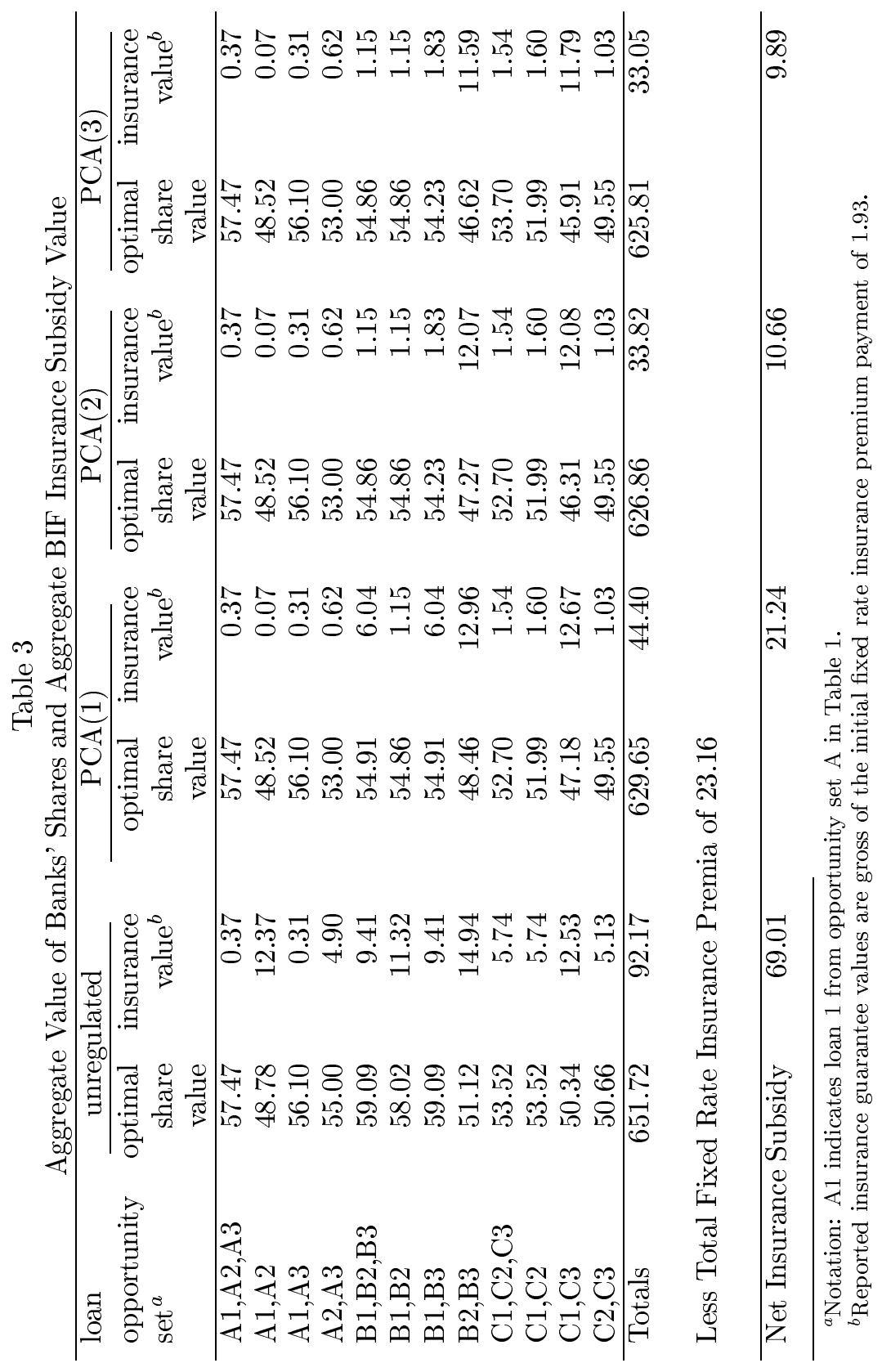




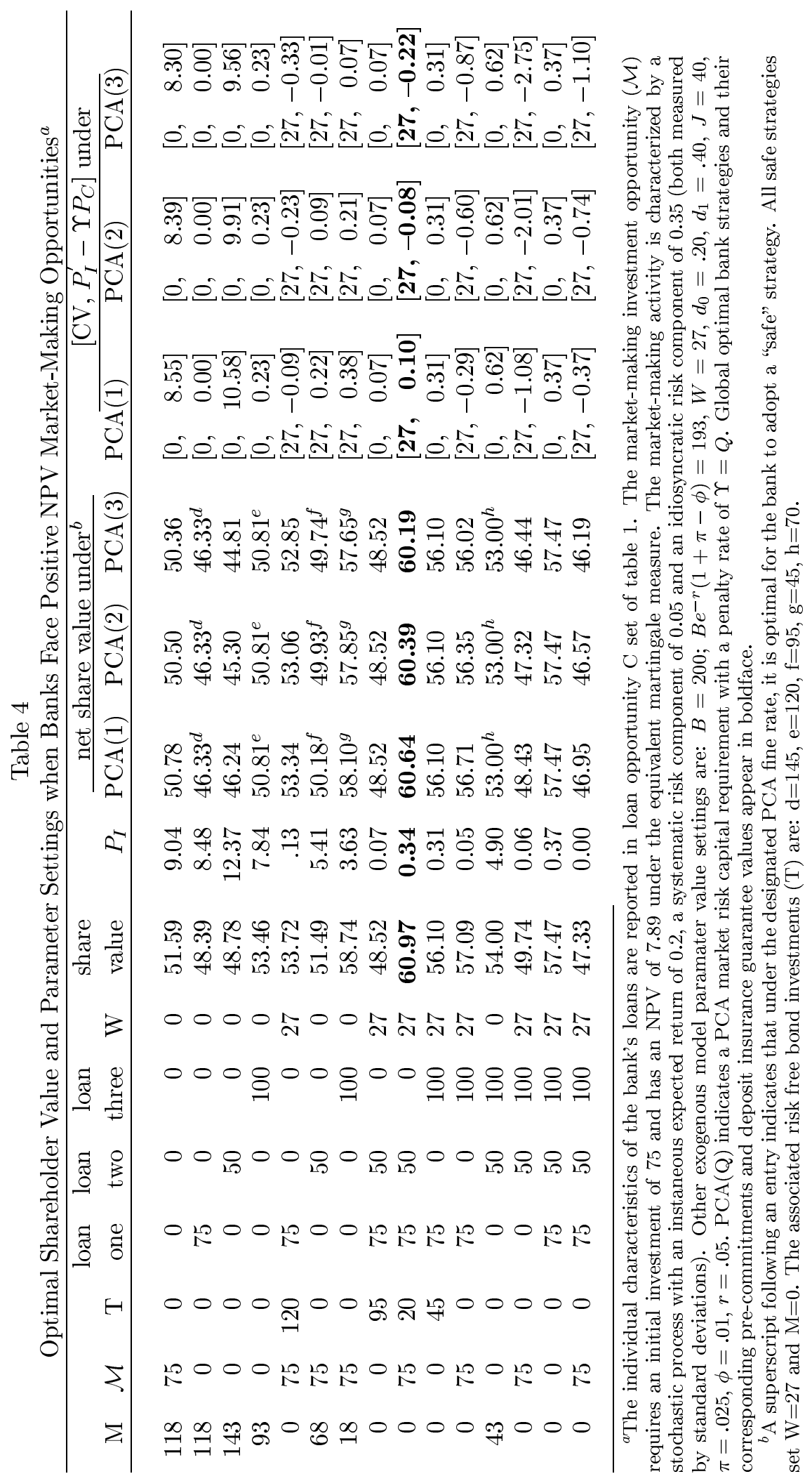

